\title{
A new species of Coahomasuchus (Archosauria, Aetosauria) from the Upper Triassic Pekin Formation, Deep River Basin, North Carolina
}

\author{
Andrew B. Heckert, ${ }^{1}$ Nicholas C. Fraser, ${ }^{2,3}$ and Vincent P. Schneider ${ }^{4}$ \\ ${ }^{1}$ Department of Geology, Appalachian State University, ASU Box 32067, Boone, North Carolina 28608-2067, USA 〈heckertab@appstate.edu〉 \\ ${ }^{2}$ National Museums Scotland, Chambers Street, Edinburgh EH1 1JF, UK 〈nick.fraser@nms.ac.uk〉 \\ ${ }^{3}$ Virginia Museum of Natural History, 23 Starling Avenue, Martinsville, Virginia 24112, USA \\ ${ }^{4}$ North Carolina Museum of Natural Sciences, 11 West Jones Street, Raleigh, North Carolina 27601-1079 USA \\ 〈vpsch@nc.rr.com〉
}

\begin{abstract}
We describe a new species of the aetosaur Coahomasuchus, C. chathamensis, based on an incomplete, but largely articulated, anterior portion of a skeleton recovered from a quarry in the Upper Triassic Pekin Formation of Chatham County, North Carolina. This is only the second documented occurrence of Coahomasuchus, with the other being the holotype of C. kahleorum Heckert and Lucas, 1999 from the Upper Triassic Colorado City Formation of Texas. Although much of the specimen is the same size as the holotype of $C$. kahleorum, the dorsal paramedian osteoderms of the North Carolina taxon are considerably $(\sim 1.3 \times)$ wider than homologous counterparts in C. kahleorum, and the ventral thoracic osteoderms are also rectangular $(\sim 1.5 \times$ wider than long), rather than square, presumably to accommodate the wider body. This is a rare instance where two articulated specimens of closely related aetosaur species are available for direct comparison of homologous osteoderms. Isolated osteoderms with similar ornamentation from the same locality indicate that $C$. chathamensis may have been one of the earliest aetosaurs to attain the broad osteoderm proportions (width:length $>3.5: 1$ ) otherwise known solely from later branching, spinose taxa such as Typothorax. The co-occurrence of Lucasuchus and Coahomasuchus in both North Carolina and Texas supports past correlations indicating an Otischalkian (Carnian) age for these strata and demonstrates that plesiomorphic, non-spinose aetosaur genera were not necessarily endemic to a single basin in North America.
\end{abstract}

\section{Introduction}

The aetosaurs form a group of moderate- to large-sized ( 1-4 m body length) quadrupedal herbivorous to faunivorous armored archosaurs restricted to strata of Late Triassic age worldwide. With the exception of Australia and Antarctica, there are aetosaur records for every modern continent (Desojo et al., 2013). Aetosaurs are important as they are one of very few Triassic lineages in the large post-Permian archosauromorph radiation (other than rhynchosaurs) that exhibits any indication of herbivory. Since Heckert and Lucas (2000) systematically revised the group, recognizing 10 valid genera and 13 species, many new taxa have been recognized (e.g., Lucas et al., 2002, 2006, 2007; Zeigler et al., 2002; Parker, 2005, 2007; Martz and Small, 2006; Parker et al., 2008; Sulej, 2010; Desojo et al., 2012; Spielmann and Lucas, 2012; Small and Martz, 2013; Heckert et al., 2015), such that the recent review by Desojo et al. (2013) recognized as many as 22 genera and 26 species. Because aetosaur armor is highly distinctive, many of these taxa are known largely to entirely from associated osteoderms, sometimes to the exclusion of other skeletal elements. Indeed, both skulls and articulated skeletons are extremely rare. In this paper, we describe an incomplete skeleton, including much of a skull, and some associated aetosaur fossils collected from a quarry operation in southeastern Chatham County, North
Carolina, that represent a new species of the aetosaur Coahomasuchus and comment on their evolutionary and biostratigraphic significance.

\section{Geologic setting}

The specimen described here comes from NCSM locality NCPALEO1902, located in a brick quarry in southeastern Chatham County, North Carolina (detailed locality data are on file at NCSM) (Fig. 1.1). Olsen (1997) and Weems and Olsen (1997) referred all Triassic sedimentary rocks in North Carolina to the Chatham Group of the Newark Supergroup. Newark Supergroup sediments were deposited in a series of rift basins extending from the present-day Gulf Coast to Canada. In North Carolina, the easternmost of these basins exposed at the surface is the Deep River Basin, which is subdivided into the northern Durham, the central Sanford, and the southern Wadesboro subbasins (Olsen et al., 1991; Fig. 1.1). The Sanford sub-basin, where NCPALEO1902 is located, is a half-graben with the primary bounding fault on the east side, and the brick quarry is in the northeastern-most portion of the Sanford sub-basin, just south of the Colon cross-structure, a basement feature that separates it from the Durham sub-basin to the north (Olsen et al., 1991; Fig. 1.1, 1.2). 


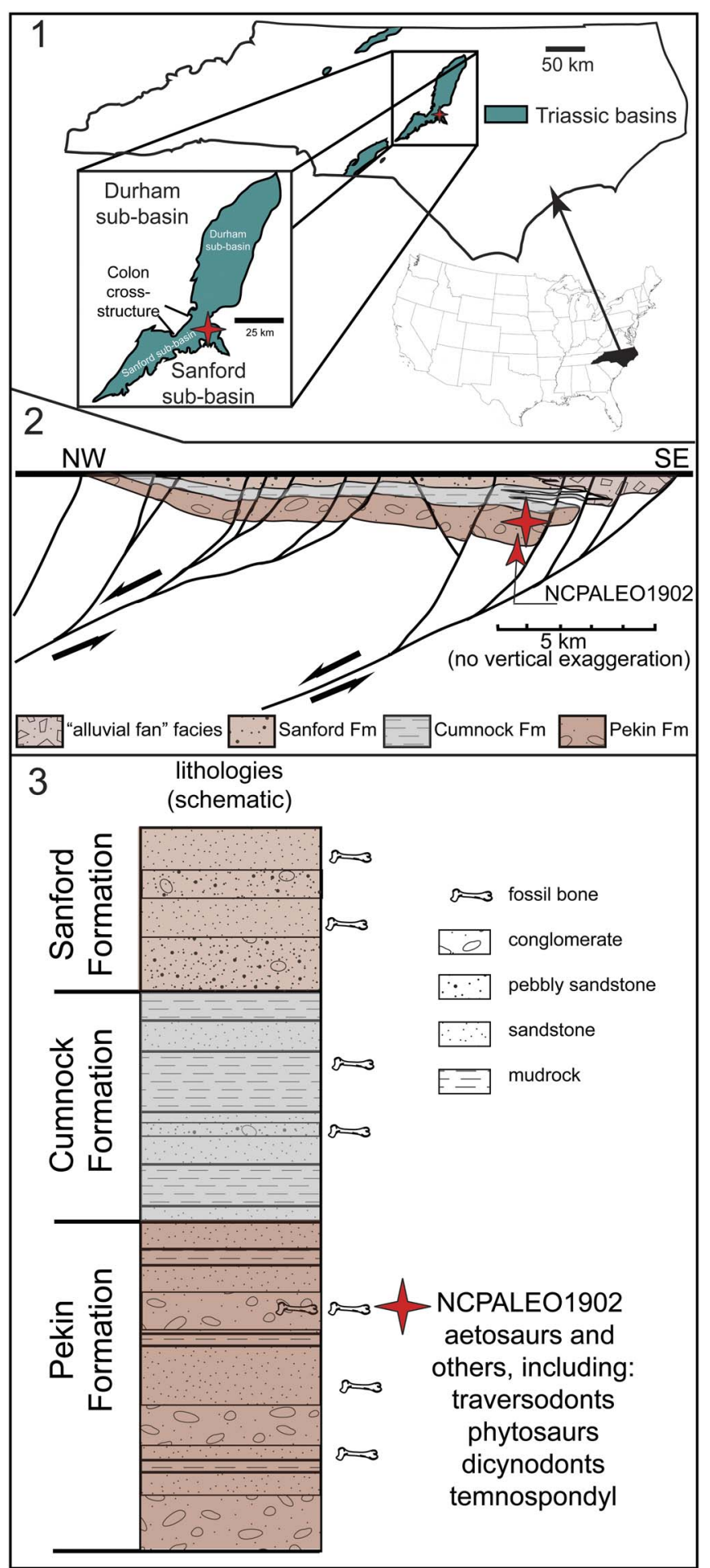

Figure 1. Index map and generalized stratigraphy of the Deep River Basin, North Carolina. (1) generalized map showing the location of the Deep River Basin in North Carolina; (2) schematic cross-section (modified from Olsen et al., 1991) showing stratigraphic position of NCPALEO 1902 in the Sanford sub-basin; (3) generalized stratigraphic section of the Sanford sub-basin showing the distribution of vertebrate localities, including NCPALEO 1902.

Sanford sub-basin stratigraphy, as originally developed by Campbell and Kimball (1923) includes, in ascending order, the Pekin, Cumnock, and Sanford formations, which increase greatly in thickness across the half-graben from west to east (Fig. 1.2, 1.3). Both the Pekin and Sanford formations are predominantly red, sandstone-dominated units sandwiched around the middle, predominantly gray and fine-grained, Cumnock Formation.

The brick operation is focused on mining clay and other fine-grained materials from a thin $(<50 \mathrm{~m}$ thick) portion of the Pekin Formation (Trp as mapped by Reinemund, 1955). As part of the operation large ( 1-5+m maximum dimension) boulders consisting primarily of crossbedded sandstone, siltstone, and conglomerate are pushed out of the way and left to weather (the softer, fine-grained sediments are mined immediately). All of the fossils reported here, and most fossils recovered from this quarry, including dicynodonts (Green et al., 2005; Green, 2012), traversodont cynodonts (Liu and Sues, 2010), the crocodylomorph Carnufex (Zanno et al., 2015; Drymala and Zanno, 2016), the aetosaur Gorgetosuchus (Heckert et al., 2015), and a largely unpublished assemblage including a phytosaur and a sphenosuchian were found in several of these isolated, massive blocks that were abandoned on the quarry floor so that precise stratigraphic data for the material is not available. The same block that yielded the aetosaur skeleton described herein also yielded a traversodont cynodont skull (NCSM 20665).

Most of the fossils were recovered in a fine-grained red siltstone, but a coarser-grained (greywacke) matrix has also yielded a few of the osteoderms described here. We interpret the coarse-grained lithologies in these blocks as channel and/or alluvial fan deposits derived from the nearby rift margin. The majority of these blocks are probably derived from a single persistent bed near the floor of current quarry operations, but determining their exact provenance beyond the level of "upper Pekin Formation" is not feasible at this time. Reinemund's (1955) map shows the area encompassed by the quarry as stratigraphically high in the Pekin Formation, but the quarry sediments lack calcareous nodules (caliche) characteristic of the uppermost Pekin Formation (P. E. Olsen, personal communication, 2015). Thus, the specimens are clearly derived from the upper half of the Pekin Formation but their exact position within the Pekin Formation is not known.

Traditionally, palynostratigraphers have assigned the Pekin Formation to the Carnian (e.g., Cornet, 1993; Litwin and Ash, 1993), and this age assignment was corroborated by vertebrate biostratigraphy (Huber et al., 1993; Lucas and Huber, 2003) and incorporated into tectonic and lithostratigraphic work (Olsen et al., 1991; Olsen, 1997; Weems and Olsen, 1997). More recent work demonstrates that at least some supposedly Carnian strata, including much of the Newark Supergroup long thought to be Carnian (e.g., Kent and Olsen, 1999, 2000) may in fact be Norian in age as the base of the Norian stage is now considered ca. $228 \mathrm{Ma}$ (Muttoni et al., 2004; Furin et al., 2006). Although the "long Norian" is disputed by some (e.g., Lucas et al., 2012), Whiteside et al. (2011, table S2) provided an estimate of $231 \mathrm{Ma}$ for the Pekin Formation, based on paleomagnetostratigraphic correlation with other Newark Supergroup sections. This estimate is a Carnian age, and consistent with both Muttoni et al.'s (2004; Furin et al., 2006) and Lucas' (2010) Triassic timescales for the Carnian. 


\section{Materials and methods}

The specimens described here were found associated in large quarry blocks, consisting primarily of crossbedded sandstone, siltstone, and conglomerate. The articulated specimen was found with the ventral surface exposed, although the original orientation of the host block is not known. Fossils are identified in the field and removed by using a rock saw to cut out blocks of matrix and fossils, which are then transported to the NCSM. There, preparation consists of removing matrix with tungstencarbide pins and air scribes, and specimens are consolidated using polyvinyl acetate $\left(\right.$ VINAC $^{\circledR}$ B-15). The specimens were photographed using a Nikon D60 camera, with images manipulated in Adobe Photoshop and drawings accomplished using Adobe Illustrator.

The material is mostly in the form of disassociated osteoderms (scutes) and occasional vertebral and limb elements, but articulated material includes an almost complete presacral skeleton, including much of the armor of one small individual. Numerous other elements, some isolated and some associated, were preserved separately in three other boulders. We recognize two distinctive aetosaur taxa in the material (Fraser et al., 2006; Schneider et al., 2011; Heckert et al., 2012), with the majority of the fossils from the same taxon as the articulated skeleton, but some representing another, larger, taxon recently named Gorgetosuchus (Heckert et al., 2015). We follow Heckert and Lucas (1999) and refer to the longitudinal series of osteoderms as "columns" and transverse series as "rows." Thus an aetosaur carapace typically consists of two columns each of paramedian and lateral osteoderms and eight or more columns of ventral osteoderms. Rows typically correspond 1:1 with vertebrae, especially in the thoracic and caudal series, although there are exceptions (Long and Murry, 1995). Osteoderms from different parts of the body are identified as "cervical, thoracic, sacral, caudal, and appendicular" as appropriate, following Long and Ballew (1985; Heckert and Lucas, 2000; Parker, 2007). We use dorsal and ventral "aspect" to describe the views of the top and bottom of the articulated skeleton, and "view" to indicate observations of elements as if in life position. The order of discussion of preserved skull elements is the same as used by Small and Martz (2013).

Repositories and institutional abbreviations.-The specimens described here, including the holotype, are reposited at the North Carolina Museum of Natural Sciences (NCSM) in Raleigh, North Carolina, where detailed locality data are also on file. The type species of Coahomasuchus kahleorum Heckert and Lucas, 1999, which is the only other specimen of the genus, is reposited at the New Mexico Museum of Natural History and Science (NMMNH), in Albuquerque, New Mexico. We also make reference to a specimen housed at the Texas Memorial Museum (TMM) in Austin, Texas.

\section{Systematic paleontology}

Superorder Archosauria Cope, 1869

Order Suchia Krebs, 1974

Suborder Aetosauria Marsh, 1884
Family Stagonolepididae Lydekker, 1887

Genus Coahomasuchus Heckert and Lucas, 1999

Type species.—Coahomasuchus kahleorum Heckert and Lucas, 1999 from the Colorado City Formation, west Texas, by original designation.

Other species.—Coahomasuchus chathamensis n. sp., described here.

Diagnosis.-Genus of aetosaur distinguished by its relatively small $(<1.5 \mathrm{~m}$ adult size) body and characterized by dorsal paramedian osteoderms with extremely faint ornamentation, especially on the presacral series, typically expressed as a subdued boss or knob from which elongate, subradial ridges emanate laterally, with smaller, and more pitted, ornamentation medially. All but the apparent small size are apomorphic for the genus.

Occurrence.-Known from the Colorado City Formation (Dockum Group), west Texas (Heckert and Lucas, 1999) and the Pekin Formation of North Carolina (described here).

\section{Coahomasuchus chathamensis new species} Figures 2-6

Holotype.-NCSM 23618, an incomplete, articulated skeleton (Figs. 2-5) from the Upper Triassic Pekin Formation, NCSM locality 1902, Chatham County, North Carolina.

Diagnosis.-A species of Coahomasuchus distinguished from the type species, C. kahleorum, by proportionately wider dorsal paramedian osteoderms ( $\sim 10$ to $35 \%$ wider for homologous osteoderms; maximum width:length ratio of 3.6 or more) and ventral thoracic osteoderms that are rectangular $(\sim 1.5 \mathrm{x}$ wider than long), not square. Autapomorphies of $C$. chathamensis include a surangular with a long ventral process extending as far as, or farther than, the dorsal process, and the wide thoracic ventral osteoderms.

Occurrence.-Known solely from the Upper Triassic Pekin Formation of Chatham County, North Carolina. The quarry yielding these specimens is in the upper portion of the Pekin Formation, which is currently considered some of the older Upper Triassic strata in the Newark Supergroup in that it is Carnian in age (Whiteside et al., 2011, table s2), see discussion in "geologic setting" for more details. Detailed locality data for NCPALEO1902 are on file at NCSM.

Description.-The holotype, NCSM 23618 (Figs. 2-5) comprises the anterior half of an articulated, dorso-ventrally crushed skeleton that has been prepared in dorsal and ventral aspect (Figs. 2, 3). The posterior half of the skull and lower jaws have been prepared in left and right lateral views as well (Figs. 4, 5). Posterior to the skull approximately 15 rows of paramedian osteoderms are evident (Fig. 3). Assuming a 1:1 ratio of osteoderm rows to vertebrae (typical, but not universal for aetosaursWalker, 1961; Long and Murry, 1995; Desojo et al., 2013; 

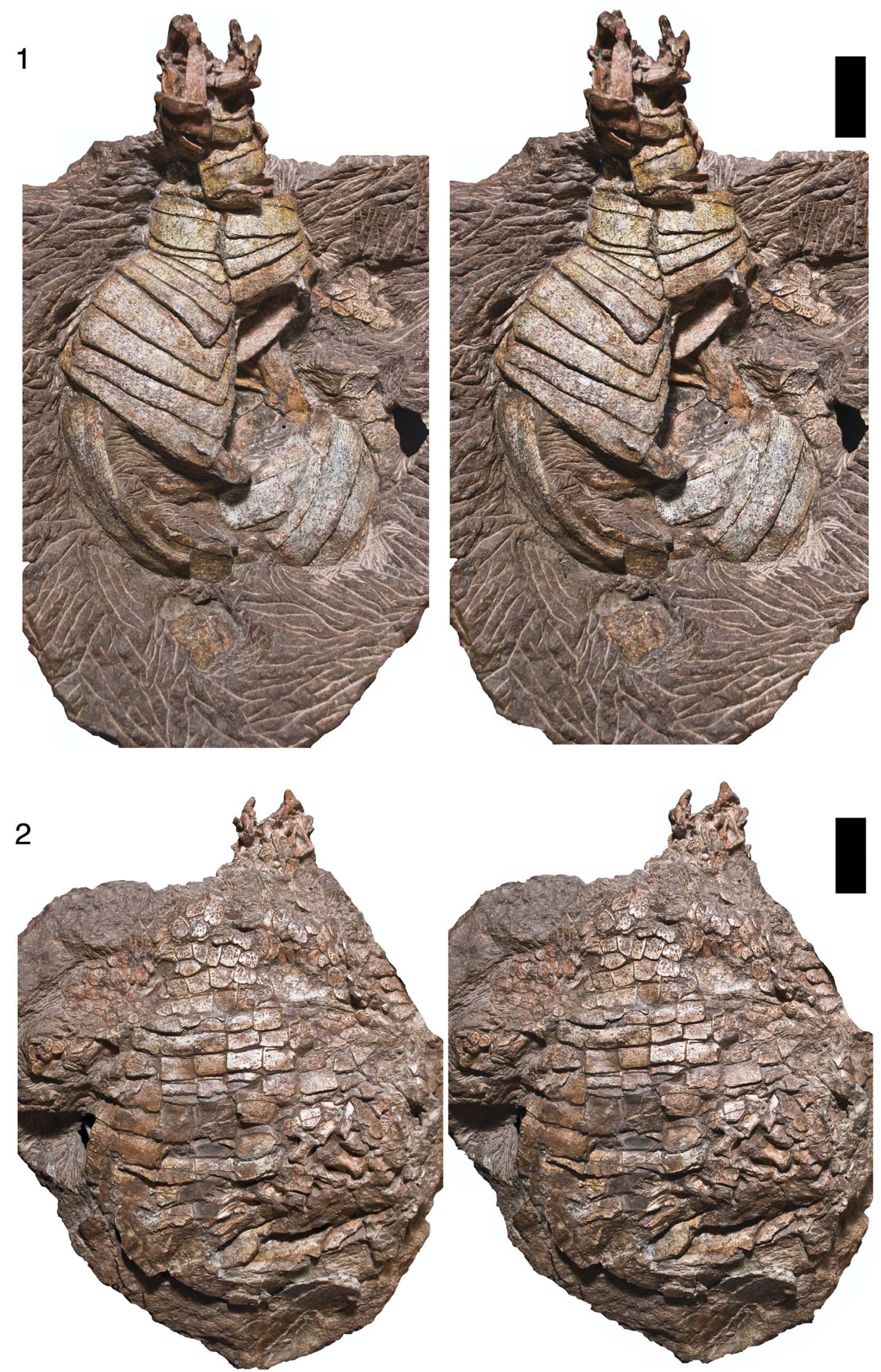

Figure 2. Stereopair photographs of the holotype specimen of Coahomasuchus chathamensis n. sp. (NCSM 23618) in (1) dorsal and (2) ventral aspects. Scale bars represent $5 \mathrm{~cm}$. 


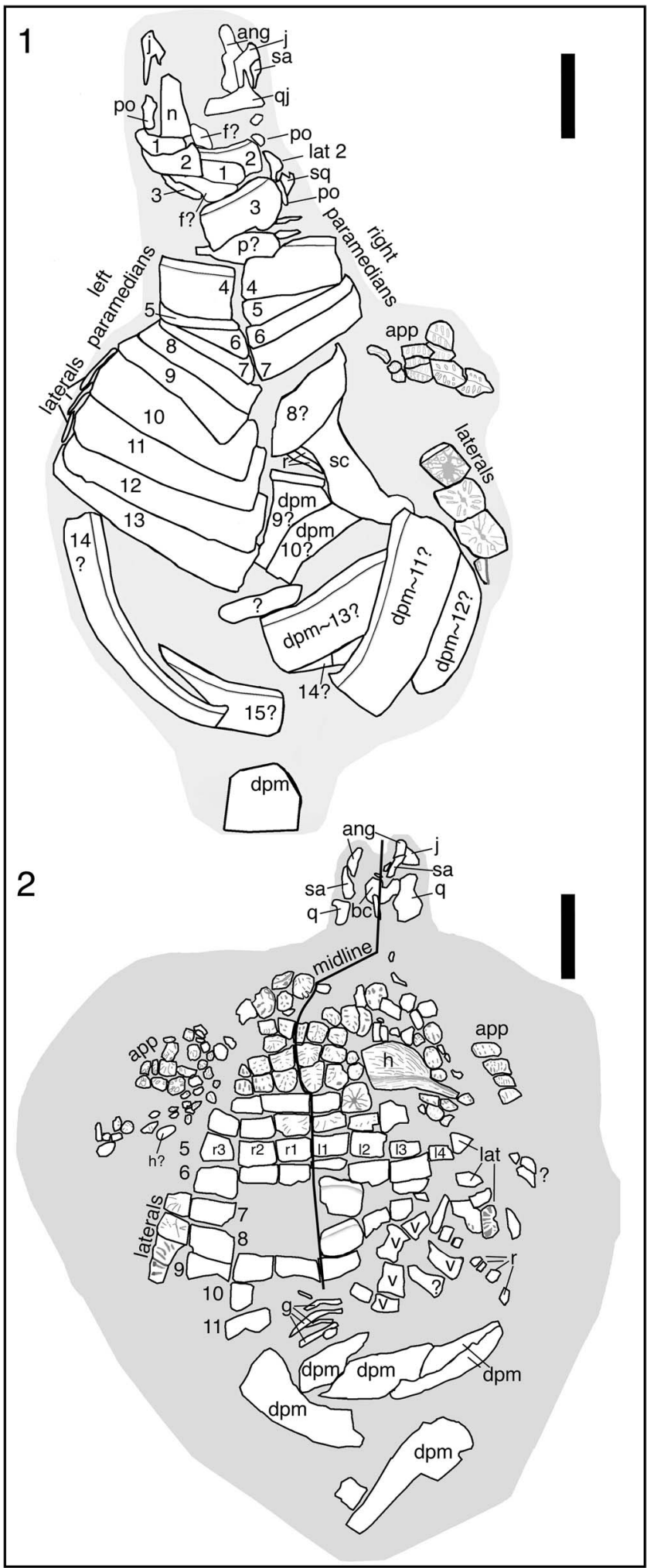

Figure 3. Interpretive sketches of the holotype specimen of Coahomasuchus chathamensis n. sp. (NCSM 23618) in (1) dorsal and (2) ventral aspects. ang $=$ angular; app $=$ appendicular osteoderms; $b c=$ braincase $; \mathrm{dpm}=$ dorsal paramedian osteoderm; $\mathrm{g}=$ gastralia; $\mathrm{h}=$ humerus; $\mathrm{j}=$ jugal; lat $=$ lateral osteoderm; $\mathrm{n}=$ nasal; $\mathrm{p}=$ parietal; $\quad$ po = postorbital; $\mathrm{q}=$ = quadrate; $\mathrm{qj}=$ quadratojugal $; \mathrm{r}=$ ribs; $\mathrm{sa}=$ surangular; $\mathrm{sc}=$ scapula $; \mathrm{sq}=$ squamosal; $\mathrm{v}=$ vertebral centrum. ? indicates uncertainty. Numbers in (1) refer to rows of dorsal paramedian osteoderms; r1/11, r2/12, r3/13, r4/14 in (2) refer to right and left, respectively, columns of ventral osteoderms. Shading indicates matrix from the block containing the skeleton. Scale bars represent $5 \mathrm{~cm}$.
Parker, 2016), approximately two-thirds of the presacral skeleton is preserved. Dorsal and ventral osteoderms are largely in articulation and some of the appendicular osteoderms covering the forelimbs are preserved (Figs. 2, 3). A few postcranial elements, including parts of both humeri and a scapula are exposed, as are several vertebrae (Figs. 2, 3). However, because much of the carapace is articulated it almost certainly includes additional postcranial elements that are concealed between the dorsal and ventral armor. Parts of the left and right forelimbs are also present, but largely obscured by appendicular osteoderms. The carapace over the right shoulder region has been compromised so that a large part of a right (?) scapula can be seen (Fig. 3.1).

The ventral surfaces confirm that the specimen has been greatly compressed, and posteriorly much of it is missing (Figs. 2.2,3.2). The overwhelming majority of the bones exposed in ventral view are osteoderms, principally of the ventral armor but including appendicular osteoderms associated with both forelimbs. From this perspective portions of both forelimbs are visible, and a few vertebrae and even the ventral surface of some paramedian osteoderms are visible where the carapace has been compromised on the animal's left side (Fig. 3.2), and a paramedian from this area was completely removed and cleared of matrix to expose its dorsal surface. The articulation between the osteoderms disintegrates about half way down the length of the body at a point anterior to the sacrum. There is no indication of any sacral or more posterior material.

Cranial elements.-We describe the preserved portions of the skull (Figs. 4, 5), which is somewhat damaged and disarticulated, and therefore difficult to interpret, in general terms before describing each of the preserved elements in more detail. For the most part, only the posterior part of the skull, from a point close to the orbits, is preserved in NCSM 23618. It is somewhat crushed, and the mandibles have rotated forward relative to the suspensorium. As a result, the quadrates are lying flat (ventral portions facing anteriorly, see Fig. 4.3, 4.4) and even below the level of the palate, and the palate has been pushed posteriorly and dorsally through the skull roof, so that it is now oriented vertically. Although there is significant disarticulation of many cranial elements, some clear associations of individual bones remain. None of the skull openings (nares, orbits, fenestrae) are intact, and we cannot say anything at all about the nares or antorbital fenestra. In general, the elements comprising the temporal region are more completely preserved, but disarticulated from one another. Because of crushing it is difficult to distinguish between fractures and true articulation margins or sutures, but it does not appear that much, if any, of the skull sutures were completely fused, so the individual was almost surely not fully grown.

Thus, in spite of crushing and disarticulation, many individual skull elements can be positively identified. These include all or parts of the right nasal, frontal, parietal, and squamosal, possibly part of the left frontal and squamosal, and all or parts of both jugals, postorbitals, quadratojugals, quadrates, and pterygoids, together with the basisphenoid (Figs. 3-5). Lower jaw elements that are discernable include portions of both angulars and surangulars (Figs. 4, 5). The descriptions of skull and jaw elements in subsequent paragraphs 

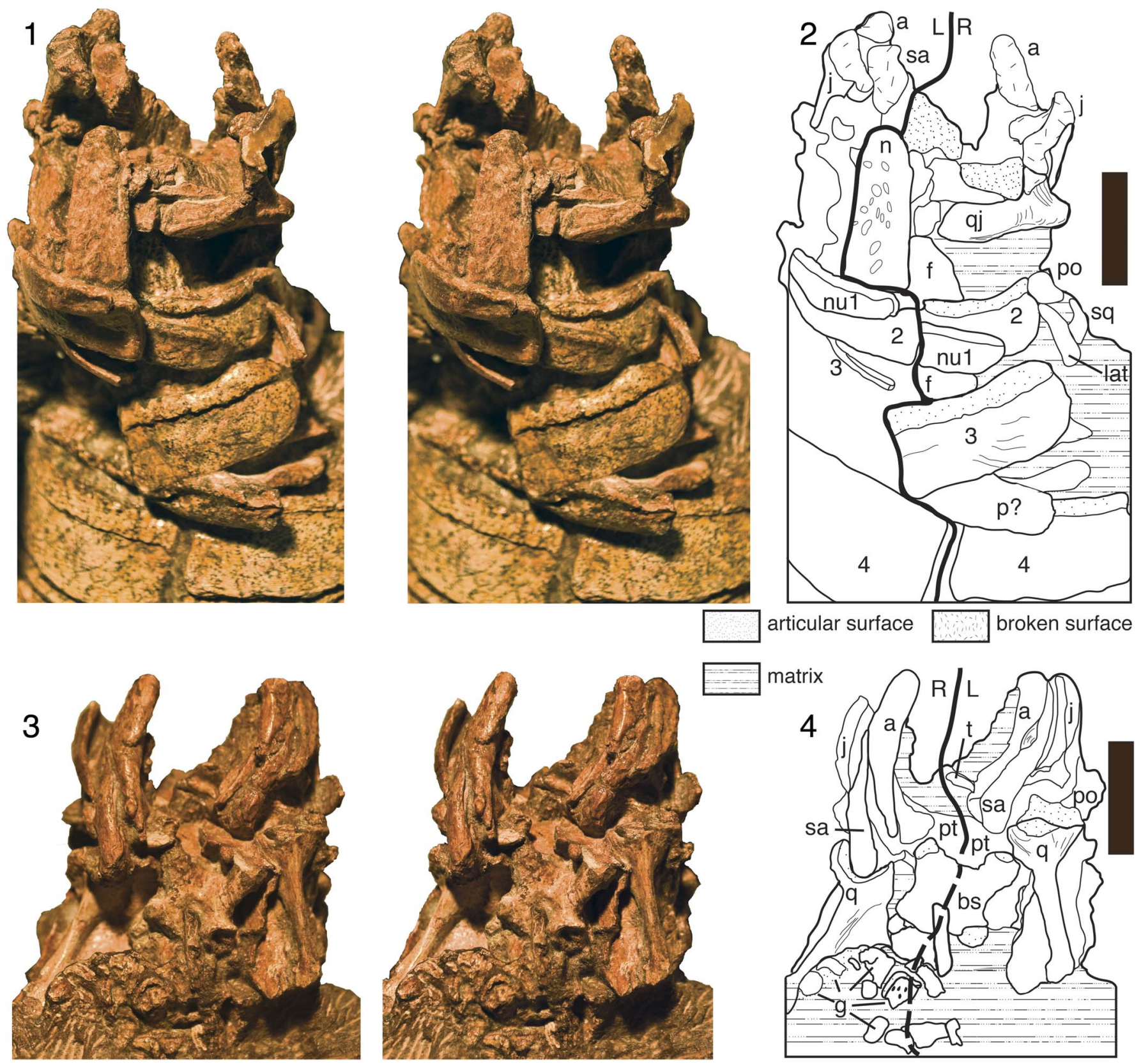

Figure 4. Stereopair photographs $(\mathbf{1}, \mathbf{3})$ and interpretive sketches $(\mathbf{2}, \mathbf{4})$ of the holotype skull of Coahomasuchus chathamensis n. sp. (NCSM 23618) in $(\mathbf{1}, \mathbf{2})$ dorsal and $(3,4)$ ventral aspects. Bold line in sketches delineates approximate position of the midline as preserved (dashed to avoid obscuring anatomy). $\mathrm{a}=$ angular; $\mathrm{bs}=$ basisphenoid; $\mathrm{g}=$ gular osteoderms; $\mathrm{j}=$ jugal; $\mathrm{L}=$ left side of midline; $\mathrm{n}=$ nasal; $\mathrm{nu}=$ nuchal (first paramedian) osteoderm; $\mathrm{p}=$ parietal; $\mathrm{pt}=$ pterygoid; $\mathrm{q}=$ quadrate; $\mathrm{R}=$ right side of midline; $\mathrm{sa}=$ surangular; $\mathrm{t}=$ tooth; numbers refer to rows of dorsal paramedian osteoderms. ? indicates uncertainty. Scale bars represent $2 \mathrm{~cm}$.

follows the same order used by Small and Martz (2013) in their recent description of the aetosaur Stenomyti.

We tentatively identify a single element on the dorsal surface as the incomplete right nasal (Fig. 4.1, 4.2). This element lacks the anterior portion and is straight in lateral or medial view. In dorsal view a faintly developed ornamentation of relatively wide diameter but extremely shallow pits is evident. The center of the element is slightly depressed along the anteromedial to posterolateral axis, medial to an anteroposterior ridge along the lateral margin. This ridge is subtlemore easily felt than seen-but would have created a slight "basin" along the midline. The nasal essentially has straight lateral and medial margins, but it is slightly broader posteriorly than anteriorly. A sliver of bone along the anterolateral margin may represent part of the right premaxilla. If we have interpreted this specimen correctly, another sliver at the posteromedial corner is probably part of the left nasal, and the element as a whole has been pushed dorsally, posteriorly, and to the left of its life position.

We provisionally interpret a flat bony surface below and posterior to the nasal(?) and nuchal osteoderms as the frontal(s) (Figs. 4.1, 4.2, 5.3, 5.4). This is probably almost entirely the 

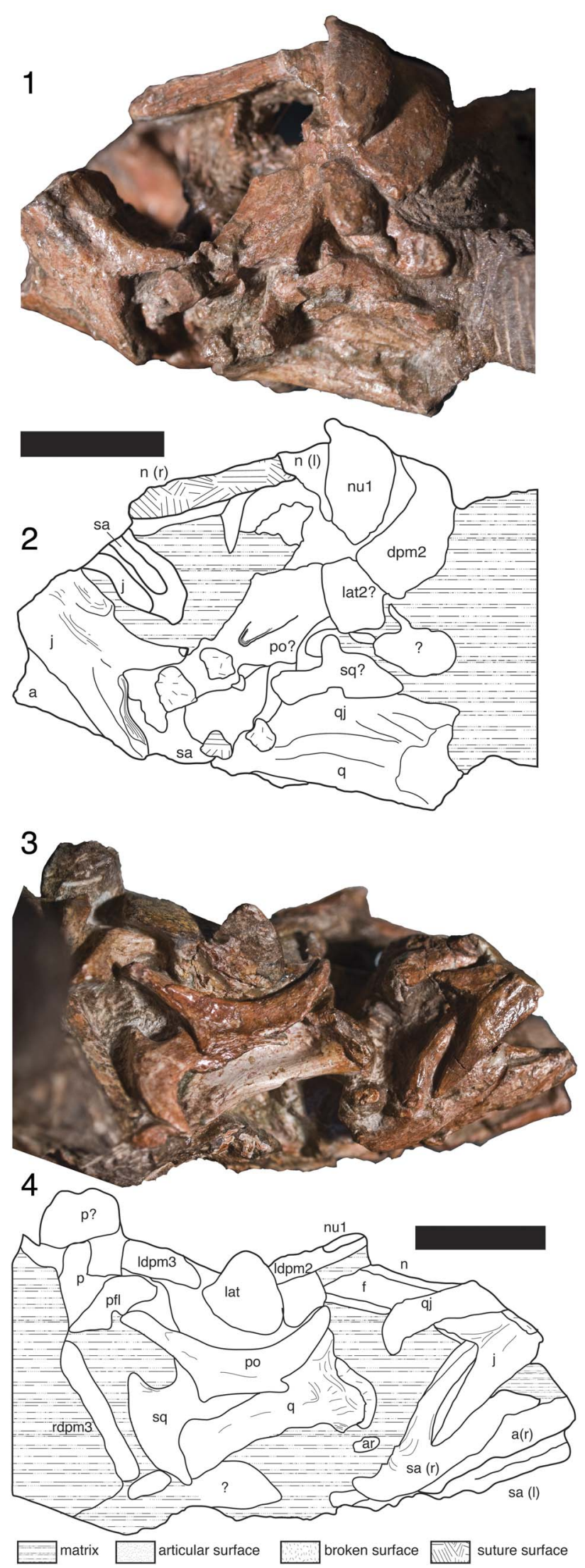

right frontal, but may include part of the left. The portion visible in dorsal view is lightly ornamented with several shallow pits like the nasal(?) and includes smaller, proportionately deeper pits and thus is more ornamented. The visible bone includes a tapering posterolateral margin we interpret as the medial margin of the orbit.

The right parietal is present, but mostly obscured by the anterior-most paramedian osteoderms (Fig. 4.1, 4.2). We interpret one portion, visible behind the displaced nuchal osteoderms, as the anterior margin of the right parietal and its suture with the posterior portion of the right frontal. Posterior to the third right paramedian osteoderm is an elongate process we interpret as the lateral portion of the posterior flange of the parietal (Fig. 5.3, 5.4). This process curves laterally toward the posterior margin of the disarticulated postorbital and squamosal.

Only the posterior parts of both jugals (Figs. 3-5) are preserved, each best seen in lateral view. They are robust elements that formed the anterior margins of the lower temporal fenestrae. Posteriorly this bone splits into well-defined dorsal and ventral processes, as in Stagonolepis, Aetosaurus, and Stenomyti (Walker, 1961; Small and Martz, 2013), but unlike other most aetosaurs for which the jugal is known (e.g., Desojo and Báez, 2007, text-fig. 5; Parker, 2016; Schoch and Desojo, 2016). A thin ridge or keel divides the two posterior processes; the more ventral process is significantly longer and more robust than the dorsally directed postorbital process.

The right postorbital (Fig. 5.3, 5.4) is gently arcuate with the addition of a poorly developed spur on a keel for its articulation with the squamosal on the posterior side. The posterior border of the orbit is slightly raised into a rim, and there is a pronounced facet on the dorsal process where it was presumably overlapped by the postfrontal. Our preferred restoration (Fig. 5.4) is based on all three elements on the right side being essentially complete, but somewhat disarticulated, with the postorbital rotated $90^{\circ}$ counterclockwise relative to the squamosal. The left postorbital is poorly and incompletely preserved (Fig. 5.1, 5.2), but does show the small, pointed posterior process but otherwise provides no additional resolution.

We interpret an "L-shaped" bone best seen in dorsal (superior) aspect as the right quadratojugal (Figs. 3.1, 4.1, 4.2, $5.3,5.4)$. The posterolateral corner is rounded and projects more ventrally than the rest of the bone. The dorsal process is clearly faceted, with an anterior facet that the postorbital overlapped and another that articulated with the squamosal dorsally and posteriorly. As preserved, it is not as tall as the postorbital, but taller than the squamosal. Anterior to the quadratojugal is a sliver of bone of uncertain affiliation that we tentatively interpret as a portion of the right dentary. Parker (2016, character 17)

Figure 5. Photographs $(\mathbf{1}, \mathbf{3})$ and interpretive sketches $(\mathbf{2}, \mathbf{4})$ of the holotype skull of Coahomasuchus chathamensis n. sp. (NCSM 23618) in $(\mathbf{1}, \mathbf{2})$ left lateral and $(3,4)$ right lateral aspects. All elements are from the side of view unless otherwise noted. $\mathrm{a}=$ angular; $\mathrm{ar}=$ articular; $\mathrm{dpm}=$ dorsal paramedian osteoderm; $\mathrm{f}=$ frontal; $\mathrm{j}=$ jugal; lat $=$ lateral osteoderm; $\mathrm{n}=$ nasal; $\mathrm{nu}=$ nuchal (first paramedian) osteoderm; $\mathrm{p}=$ parietal; $\mathrm{pfl}=$ parietal flange; po = postorbital $; \mathrm{q}=$ quadrate $; \mathrm{qf}=$ quadrate foramen $; \mathrm{qj}=$ quadratojugal $;$ $\mathrm{sa}=$ suragular; $\mathrm{sq}=$ squamosal; numbers refer to rows of osteoderms; ? indicates uncertainty. (l) and (r) refer to left and right sides, respectively. Scale bars represent $2 \mathrm{~cm}$. 

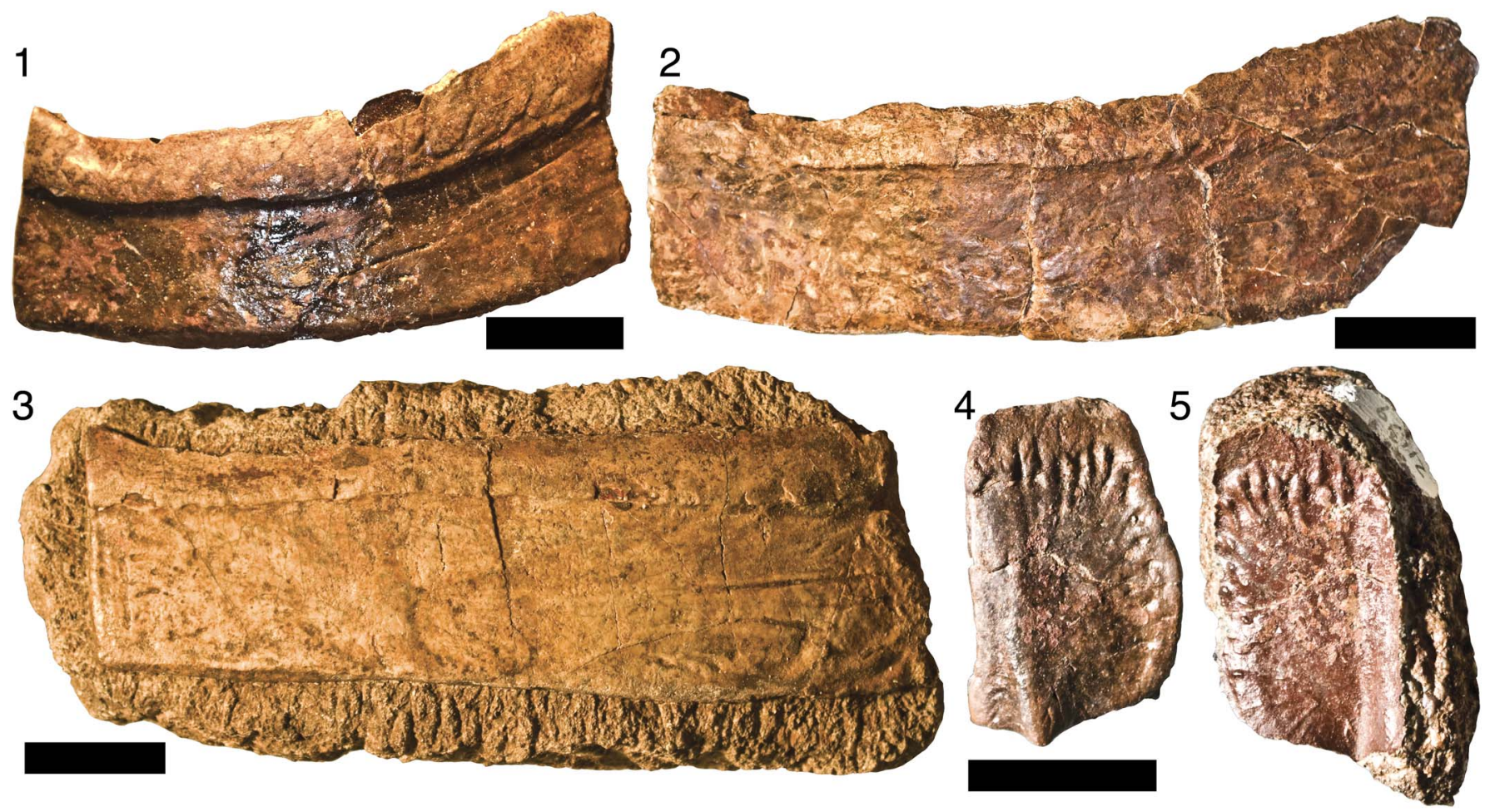

Figure 6. Dorsal paramedian (1-3) and lateral $(\mathbf{4}, \mathbf{5})$ osteoderms referred to Coahomasuchus chathamensis from NCPALEO 1902. All are from the right side of the body. (1) Anterior dorsal or posterior cervical paramedian (NCSM 21707) in dorsal view. (2) Anterior dorsal (thoracic) paramedian osteoderm (NCSM 16444-1) in dorsal view. (3) Thoracic dorsal paramedian in matrix (NCSM 19675) in dorsal view. (4) Right lateral osteoderm (NCSM 21179) in external ( dorso-lateral) view. (5) Impression of (4) in matrix from the site. Scale bars represent $2 \mathrm{~cm}$.

coded Coahomasuchus as having a derived state wherein the jugal underlies the quadratojugal, which we interpret as possible based on the posteriorly forked processes of the jugal described previously, but which we cannot determine unambiguously on this specimen. The left quadratojugal is less well preserved and harder to see than the right because of the associated squamosal (?) and quadrate (Fig. 5.1, 5.2), but preserves the distinctive ventral projection.

The right squamosal (Figs. 3.1, 5.3, 5.4) is a complexly shaped bone that is very similar to that of most other aetosaurs. It possesses a pronounced posterolateral hook that would have formed the posterodorsal margin of the tympanic fossa. A shorter posteromedial process contributed to the posterolateral margin of the upper temporal fenestra and contacted the parietal. The long anteroventrally directed process is largely covered by the right postorbital, and as a consequence details of the articular facets for the postorbital and quadratojugal are obscured. A possible left squamosal is evident in lateral view (Fig. 5.1, 5.2) but poorly preserved and adds nothing to the discussion here.

The quadrates (Figs. 3.2, 4.3, 4.4, 5) are large strut-like elements that, although displaced downwards below the level of the basipterygoid, are still closely associated with the posterior ends of each mandible. These are some of the largest and most robust elements preserved in the skull. A prominent ridge runs dorso-ventrally along the posterior surface. The robust, approximately circular, articular condyle is best seen on the right side only slightly displaced from the articulation with the mandibular condyle. A deep anteromedial flange best seen on the left side is still in close association with part of the posterolateral flange of the pterygoid (quadrate process of the pterygoid sensu Desojo and Baez, 2007). Unfortunately, we cannot unambiguously identify the quadrate foramen from the preserved material.

Palate.- In ventral view large portions of both pterygoids are still preserved in broad articulation with each other along the midline (Fig. 4.3, 4.4), although most of these elements are now vertically oriented and only visible in anterior aspect. The contacts with the stout basipterygoid processes are damaged on both sides, obliterating details of the nature of this articulation. The quadrate process of the pterygoid (sensu Desojo and Baez, 2007) is evident in posterior view medial to the left quadrate.

Braincase.-On its ventral surface, the basisphenoid exhibits a pronounced fossa, or basisphenoid recess (Figs. 3.2, 4.3, 4.4), that is relatively short and deep. The basipterygoid processes are comparatively long, but only slightly separated from the basal tubera (plesiomorphic condition of Parker, 2016). These tubera are stout and posteriorly directed, but their posterior facets are not well preserved and their relationship with the basioccipital is obscured by a small bone (hyoid?) laying on the ventral surface of the braincase. The metotic fissure may be visible on the lateral surface of the left basisphenoid (Fig. 4.3, 4.4). Comparisons to the holotype of Coahomasuchus kahleorum (Heckert and Lucas, 1999; Desojo and Heckert, 2004; see also Parker, 2014) are difficult due to relatively poor preservation of NCSM 23168.

Lower jaw.-The posterior ends of the mandibles are preserved on both sides with portions of each angular and surangular still in articulation with each other as well as being closely associated with the condyle on the quadrate (Figs. 3-5). 
We consider a sliver of an element anterior to the quadratojugal as part of the dentary. This element is only visible in occlusal view and bears the medial portion of as many as three tooth sockets (only one well preserved) and as such is strongly suggestive of it being the dentary. However, sometimes in basal archosauriforms the splenial contributes to the medial margin of posterior tooth sockets, so we cannot unequivocally exclude the possibility that it represents the anteromedial portion of the splenial (e.g., some phytosaurs, see Heckert et al., 2013), but this is not known to occur in aetosaurs. It is not identified on any figures because it is tucked so deeply into the preserved specimen that it is not visible in any of the views we can provide.

The surangular is extended posteriorly into a short retroarticular process. As best seen on the right side (Fig. 5.3, 5.4), it splits anteriorly into two processes that bound the posterior half of the mandibular fenestra. There is a shallow groove along the dorsal margin of the angular that receives the ventral process of the surangular so that the articulation between the two elements is more of a "tongue and groove" and less a simple butt joint. A small fragment of bone lying immediately above the retroarticular process may represent the articular (Fig. 5.4).

Dentition.-All or parts of six teeth are associated with the specimen. None are in place, having fallen out of their sockets, but all are in the oral cavity in that they are between the mandibles and in front of the (now) vertically oriented palate. They are small (millimeter scale), but of a size consistent with that of the specimen. Furthermore, some preserve roots and thus were not shed and therefore are unlikely to be from another animal. The most clearly seen is in the oral cavity when viewed in ventral aspect (Fig. 4.3, 4.4). All are essentially conical, not bulbous, and lack serrations. Some are only slightly recurved, with the curvature restricted to a point near the apex, whereas other teeth are more recurved, in a pattern similar to that of phytosaurs. None are particularly tall, with the most complete crown no more than twice as tall as its basal length. Fragments of additional, similarly-sized, teeth are embedded in the mandibular sockets, but are not preserved sufficiently to describe further.

Axial skeleton.-The largely articulated carapace obscures much of the axial skeleton, as it does in Coahomasuchus kahleorum (Heckert and Lucas, 1999) and other articulated aetosaur specimens. In dorsal aspect (Figs. 2.1, 3.1), two rodlike elements that are probably ribs are visible, as is much of the shaft of the right (?) scapula and a fragmentary neural arch that lies posterior and ventral to the seventh paramedian and is not visible in the figures.

In ventral aspect more of the axial skeleton is visible, including several centra and fragments of ribs and gastralia (Figs. 2.2, 3.2). A disrupted area in the left portion of the body cavity reveals parts of six dorsal centra, all in ventral view. Four are nearly in articulation, and each of these is somewhat shorter $(\sim 15 \mathrm{~mm}$ long) and stouter (up to $6 \mathrm{~mm}$ across the middle of the centrum) than the more complete of the other two centra, which is significantly longer $(\geq 20 \mathrm{~mm})$ and has a more pinched ( $\leq 5 \mathrm{~mm}$ wide) centrum. The more elongate dorsal centrum is unlike the known centra of $C$. kahleorum in possessing a keel consisting of an extremely narrow ridge along the ventral surface (Fig. 2.2). A few nearby fragments appear to be portions of the ribs, as they have ovoid cross-sections and are parallel to one another. All are strongly displaced from the midline of the carapace, and so their anatomical position within the skeleton is unclear.

Near a gap in the posterior ventral carapace along the midline there are the remnants of three bones we interpret as gastralia as they are rod-like and more gracile than the ribs. None are complete, but the best example preserves a typical $120^{\circ}$ concave posteriorly chevron-like shape, similar to that documented in Typothorax coccinarum (Heckert et al., 2010). It is not clear if any of the other elements are the more medial gastral elements, but this is the second report of gastralia in aetosaurs. Nesbitt (2011) mistakenly coded aetosaurs as lacking gastralia, but we suspect that this is more likely an artifact of preservation.

Appendicular skeleton.-Only the anterior portions of the appendicular skeleton are preserved, and even these are largely covered by armor. We are able to provide brief descriptions of the scapula and humerus, however.

Scapula.-A portion of one scapula, which we interpret as the right, is visible through the disrupted armor on the right side of the carapace in dorsal aspect (Figs. 2.1, 3.1). The visible portion includes most of the shaft, but no glenoid (which is under a displaced paramedian osteoderm) or distal-most extremity of the blade (also under osteoderms), and it lies over parts of the exposed two ribs. The blade expands in both directions from the distal shaft, with the posterior expansion beginning lower on the shaft than the anterior expansion.

Humerus.-Much of the left proximal humerus and shaft is visible in ventral aspect (Figs. 2.2, 3.2). Proximally, the head is convex, with an anterior margin that slopes down to the deltopectoral crest and a posterior margin that intersects the shaft to form a broad $\left(140^{\circ}\right)$ angle. The deltopectoral crest is large but not particularly prominent or distinct, and is expressed as a wider region on the anterior portion of the bone. The distal humerus is not exposed. Comparison to the right side, which is almost completely encased in armor other than parts of the head and distalmost portion, demonstrates that the humerus was probably $\sim 70 \mathrm{~mm}$ long. Appendicular osteoderms cover other elements, although a sliver of either the left ulna or radius may be exposed posterior to the humerus on the ventral surface.

Armor.-The armor of the holotype specimen is exposed in both dorsal and ventral aspects, and includes much of both columns of the anterior dorsal paramedian osteoderms, some lateral osteoderms, many ventral osteoderms, and extensive, articulated appendicular armor that obscures most of the forelimbs, as well as a posterior paramedian removed during preparation. There are a few small, poorly preserved osteoderms posterior to the skull in ventral view that may represent gular osteoderms similar to those of Coahomasuchus kahleorum (Fig. 4.3, 4.4). In addition to the articulated specimen, there are a variety of osteoderms represented in the material that we refer to Coahomasuchus, including isolated paramedians, laterals, ventral, and appendicular osteoderms. Of these, three paramedians and a representative lateral osteoderm are illustrated in Figure 6. Most of the paramedians, including one taken from the 
articulated specimen, are similar to each other and, although they vary in shape, the ornamentation is consistent and they unequivocally represent the same species. The carapace is not from a mature specimen as the largest paramedian osteoderm from the holotype is only about two-thirds the size of NCSM 21137 , the largest disassociated osteoderm.

The articulated carapace.-Both columns of dorsal paramedian osteoderms are at least partially exposed in dorsal view, with the left column more complete than the right. All are demonstrably wider than long, and most display some degree of gentle transverse arching. As is the case in the holotype of Coahomasuchus kahleorum, it is difficult to see any ornamentation on the cervical and anterior thoracic paramedians. When present, it consists almost entirely of elongate, subradial grooves with little or no pitting, and all the pitting is confined to the medial side of the center of ossification. Similarly, the bosses or dorsal eminences ("center of ossification") are extremely reduced and only just discernable in posterior view. Each boss is extremely low and rounded, and antero-posteriorly longer than wide so it forms a keel. The actual relief of the structure is so low that it is easier to feel the topography than to see, let alone illustrate, it, but its shape is clearly delineated in the slightly disarticulated (most posterior) left osteoderm in Figure 2.1 (identified as 14? in Fig. 3.1). The boss is always located much closer to the midline than the lateral margin.

The first two rows of paramedian osteoderms are well preserved except that the first osteoderm in the right column is displaced posteriorly onto the second osteoderm (Figs. 2.1, 3.1, $4.1,4.2)$. The first pair of paramedians appears to correspond to "nuchal" osteoderms, in that they lack lateral osteoderms, and probably sat directly on the parietal in life. These nuchals are relatively wide, but similar to the anteriormost osteoderms in the holotype of C. kahleorum (Heckert and Lucas, 1999, fig. 3).

The third row of paramedian osteoderms is displaced ventrally on the left side but well exposed on the right, where the radially distributed, elongate grooves are among the bestpreserved on the specimen. Beginning with what we interpret as the fourth row, pairs are again easily identified for four rows (through the seventh row). Posterior to this the cervical to anterior dorsal left osteoderms are the best preserved, and articulated for another six rows (rows 8-13; Fig. 3.1). The eighth(?) right dorsal paramedian is displaced and rotated into the body cavity, and parts of three right dorsal paramedians that are displaced and covered by matrix are posterior to it (Fig. 3.1). All of one (the fourteenth?) and parts of two (rows 15 and 16?) other left dorsal paramedians are preserved, but detached from the more anterior osteoderms. All or part of four more right dorsal paramedians appear to represent this region of the body (approximately rows 11-14?) and these are closely associated with four essentially square, articulated right lateral osteoderms. The most posterior osteoderms are the widest (approximately $90 \mathrm{~mm}$ wide).

Lateral osteoderms.-Relatively few lateral osteoderms are preserved and visible. Throughout the specimen, lateral osteoderms possess a more-or-less radial ornamentation of comparatively deeply incised pits emanating from near the center of the osteoderm surface. All are essentially flat and this ornamentation is deeper and better defined than in the dorsal paramedians.
The first preserved lateral is actually embedded with the skull elements, situated dorsal to the right postorbital (Fig. 5.3, 5.4). This osteoderm is relatively D-shaped, with a straight medial margin and a rounded lateral margin. The ornamentation is not discernable, but, like the first dorsal paramedian, it lacks an anterior bar. Portions of at least two lateral osteoderms are slightly exposed posterior to the skull on the left side.

Further posteriorly, the edges of three laterals are apparent lateral to left dorsal paramedians 10-12 (Figs. 2.1,3.1). The four laterals on the right side (only 3 of which are visible in dorsal aspect) probably pertain to the nearby paramedians, tentatively interpreted as rows 10-13, but exact matches are not clear (Figs. 2.1, 3.1). These laterals are very slightly asymmetrical, with a weakly defined center of ossification slightly medial to the middle of the osteoderm. This forms an elongate ridge that separates the osteoderm into a narrower dorsal flange and wider lateral flange.

Ventral osteoderms.-Anterior to the pectoral girdle the ventral armor comprises more rounded, less polygonal osteoderms that are deeply incised with a radial pattern of ovate pits (Figs. 2.2, 3.2). After a transitional zone of two rows of slightly more quadrangular osteoderms that more or less corresponds to the pectoral girdle (exposed anterior to the head of the left humerus-Fig. 3.2), the thoracic ventral armor consists of at least six and as many as eight columns of osteoderms. These are all rectangular and slightly wider than long. Articulation impedes precise measurement, but typical width:length ratios are $\sim 1.5-2$. Where preserved, all possess a radial pattern of pits emanating from the center of the osteoderm. This patterning is much fainter (smaller, less deeply incised pits) on the thorax than it is on the more anterior ventral osteoderms. The fifth through seventh row of osteoderms posterior to the pectoral girdle indicate the presence of eight columns, exposed as the fourth column on the right side (Fig. 3.2). These osteoderms are much more deeply incised and are extremely similar to the lateral osteoderms exposed on the opposite side. These rows are incompletely preserved, and the quality of preservation diminishes posteriorly so that only a single osteoderm from each of the tenth and eleventh rows is evident.

The primary difference between the ventral armor of NCSM 23168 and the holotype skeleton of $C$. kahleorum is that the ventral osteoderms of NCSM 23168 are more rectangular and less square (compare to Heckert and Lucas, 1999, fig. 4). Although C. kahleorum has as many as 10 columns of osteoderms, the rows with 10 columns are more posterior than the ones preserved here, so the presence of only eight rows in C. chathamensis may be an artifact of preservation.

The NCSM specimen also appears to have more organized pre-pectoral armor lacking the hexagonal ventral osteoderms of C. kahleorum, although this difference could well be taphonomic in nature if those rows are simply not preserved in the NCSM specimen.

Appendicular osteoderms.-There are appendicular osteoderms on both the dorsal and ventral surfaces of the right side, suggesting that the right forelimb is largely complete. There is a string of at least fourteen approximately rhomboid appendicular osteoderms associated with the right forelimb on the dorsal side (Figs. 2.1, 3.1). These osteoderms overlap one another but have a 
longitudinal keel (probably directed proximo-distally in life) and several $(\sim 8-10)$ relatively coarse, distinct pits radiating away from the keel. Most are imbricated so that no single appendicular osteoderm is completely exposed, but the shape of all appears to be a rounded, slightly elongated hexagon that is as much as $15 \mathrm{~mm}$ long and $8 \mathrm{~mm}$ wide. The appendicular armor is evident on both limbs in ventral view, where it essentially covers the right limb completely and the left distal forelimb (Figs. 2.2, 3.2). These osteoderms are smaller (generally $\leq 10 \mathrm{~mm}$ maximum dimension), more ovoid, and lack the distinct keel on the long axis, although they do still possess several well-defined, albeit smaller, pits. The right limb appears to be folded, with the forelimb directed anteromedially from the elbow joint. A row of appendicular osteoderms anterior and medial to the left humerus may indicate the presence of the left distal forelimb.

Referred material.-Isolated fragments of various aetosaurian postcranial elements have been recovered from the locality, but only the elements assigned to NCSM 23618 can be unambiguously referred to $C$. chathamensis. All of the following specimens exhibit distinctive features of Coahomasuchus, specifically that the dorsal paramedian osteoderms are relatively wide with an extremely faint ornamentation that, lateral to a subdued boss, consists of fine, elongate, subparallel grooves and ridges. Almost all are slightly larger than those known from either holotype skeleton, but given our lack of knowledge of the ontogenetic state of those skeletons, they probably represent somewhat larger, presumably older individuals. Only a few ventral and appendicular osteoderms are represented in this material and we did not observe any details of these osteoderms that modified our interpretations of osteoderm homology in the holotype.

Associated dorsal osteoderms.- The majority of the specimens represent paramedian osteoderms and are generally much wider than long, with exceptionally low dorsal eminences (Fig. 6.1-6.4). In the case of each paramedian, the anterior edge bears a smooth facet, the anterior bar, which was overlapped by the posterior edge of the preceding osteoderm. On some paramedian osteoderms, the anteromedial corner of the anterior bar is developed into a short spur (anteromedial projection of Parker, 2016). The lateral margin lacks a strong anterolateral projection sensu Parker (2016). The ornamentation is rather weakly expressed in most specimens, and takes the form of radiating pits that are sometimes developed into shallow grooves. The development of continuous grooves is particularly evident on the lateral osteoderms and the lateral edges of the broadest paramedians, whereas strong pitting is most commonly seen on the medial portion of the paramedians. The ornamentation radiates from a point about two thirds of the way back from the anterior edge and along the line of angulation, closer to the midline than the lateral edge of the osteoderm, the "center of ossification" of Martz and Small (2006). As in the holotype, the grooves tend to be situated on the lateral side of the angulation and almost all of the pits on the medial side. The boss is very weakly developed, but sometimes takes the form of an extremely low ridge that is typically situated close to the point of ornament radiation, with the highest point somewhat anterior to the posterior margin of the osteoderm.

Associated paramedian osteoderms come from many parts of the skeleton, including the posterior cervical or anterior dorsal series (Fig. 6.1), an anterior dorsal paramedian (Fig. 6.2), and a more thoracic or "trunk" paramedian (Fig. 6.3). Some of the osteoderms possess a slight keel or strut, but most do not, and this strut does not substantially thicken the osteoderm, so we interpret this as retaining the plesiomorphic (unkeeled) condition of Parker (2016) and previous workers. In the preserved specimens it appears that the anterolateral portion of the paramedian would overlap the lateral osteoderm. Where preserved, the posterolateral corner forms a right angle, so that the lateral margin is relatively straight in dorsal view (NCSM 21707; Fig. 6.1) — the "cut-off" corner in NCSM 16444-1 (Fig. 6.2) is an artifact-the specimen is broken there.

Lateral osteoderms.- - In the assemblage of isolated osteoderms, there are many fewer lateral osteoderms preserved than paramedians, just as was the case with the articulated holotype specimen. Relatively few of these are as equidimensional as those described previously. Instead, these isolated laterals match the posterior laterals (especially caudal laterals) of C. kahleorum (Heckert and Lucas, 1999). Specifically, they are longer than wide, with a narrower dorsal flange and a wider lateral flange, the latter bearing a well-developed pattern of elongate pits, grooves, and ridges emanating anteriorly and laterally from a longitudinal keel that projects slightly posteriorly as a small projection, although it is less spinous than the lateral "spikes" of many aetosaurs. In the holotype of $C$. kahleorum laterals posterior to approximately row 9 are markedly asymmetrical, with a narrower dorsal flange and a wider lateral flange (Heckert and Lucas, 1999, fig. 3; Parker, 2016). Pitting is distributed radially and emanates from a longitudinal dorsal ridge; many of these osteoderms are gently flexed beneath this keel as well. The ornamentation of the lateral osteoderms is generally more deeply incised than on comparably long dorsal paramedians.

One lateral morphotype is characterized by a weakly developed longitudinal ridge that terminates in a slightly raised boss (Fig. 6.4, 6.5). In this morphotype, there is no development whatsoever of a spike. The lateral osteoderms on the articulated specimen also lack any well-developed spike, and the association of this morphotype of lateral osteoderm with the paramedians described above is unequivocal. Several specimens were freed from the matrix in one piece, so that the matrix provides a natural mold of the external surface of the osteoderm (Fig. 6.5).

Etymology.-The specific epithet, chathamensis, is for Chatham County, North Carolina, where this and many other Triassic fossils have been recovered.

Materials.-In addition to the holotype, we tentatively refer many other osteoderms and associated postcrania from the same locality to $C$. chathamensis. These include the following (all are NCSM specimens): Dorsal paramedian osteoderms: 16444-1, right posterior presacral dorsal paramedian (Fig. 6.2); 16444-2, left? posterior presacral dorsal paramedian; 16472, dorsal paramedian; 19302, right posterior presacral dorsal paramedian; 19675, right thoracic dorsal paramedian osteoderm in matrix block (Fig. 6.3); 21602, incomplete right dorsal paramedian; 21707, anterior right dorsal paramedian (Fig. 6.1). Lateral paramedian osteoderms: 19751, left lateral; 20829, right lateral; 21145, left(?) lateral; 21179, right lateral osteoderm in matrix (Fig. 6.4, 6.5): 21181, right cervical(?); 20739, left lateral. Ventral osteoderms: 19303, 
20799. All are from NCSM locality NCPALEO1902, albeit were recovered in separate blocks from the holotype and doubtless represent at least one, and possibly multiple, other individuals.

Remarks.-In the following paragraphs, we highlight similarities and differences of the holotype of Coahomasuchus chathamensis with other known aetosaurs. We divide this discussion into a brief summary of our interpretation of the skull and lower jaws, which are infrequently found with aetosaur specimens and not well understood, and a section on the osteoderms. The osteoderm discussion is critical because osteoderms are extremely important in understanding the taxonomy of aetosaurs (many taxa are known solely from osteoderms-Desojo et al., 2013; Heckert et al., 2015; Parker, 2016), and indeed, despite the completeness of this specimen, it is the osteoderms that verify its assignment to Coahomasuchus.

Skull and jaws.- Skulls of aetosaurs remain relatively rare in the Upper Triassic fossil record (Desojo et al., 2013), and are much rarer than those of coeval taxa such as phytosaurs (e.g., Long and Murry, 1995). Thus, the holotype skull of Coahomasuchus chathamensis, while incomplete, somewhat disarticulated, and difficult to interpret, retains important information. This is especially true because the skull of Coahomasuchus kahleorum is even more fragmentary (Heckert and Lucas, 1999; Desojo and Heckert, 2004; Parker, 2016).

Relatively well-preserved and described skulls are known for several of the less derived aetosaurs, including Stagonolepis robertsoni (Walker, 1961; Gower and Walker, 2002) and S. olenkae (Sulej, 2010), Aetosaurus (Walker, 1961; Schoch, 2007), Neoaetosauroides (Desojo and Baéz, 2007), and Stenomyti (Small and Martz, 2013). More derived aetosaurs are well represented by incomplete skulls of Desmatosuchus (Case, 1922; Small, 2002; Parker, 2005) and Longosuchus (Sawin, 1947; Parrish, 1994), undescribed skulls of Typothorax (Heckert et al., 2010; Parker, 2016) and a particularly complete skull and lower jaws of Paratypothorax (Schoch and Desojo, 2016). We rely on these authors' descriptions for comparison, although we have examined many of these specimens first-hand as well.

Since Walker's (1961) exhaustive treatment of the skull of Stagonolepis, many authors have considered that morphology to represent the aetosaurian bauplan, and many aetosaur skull reconstructions, even if skull material was not known or poorly preserved, were clearly based on Walker's concept of Stagonolepis (e.g., Bonaparte, 1967; Long and Murry, 1995; Heckert and Lucas, 1999). Desojo and Baéz (2007) were the first modern workers to systematically evaluate the skulls of multiple taxa and show that there was considerable diversity of aetosaur skull morphologies, an idea further developed by Desojo et al. (2013). We are not prepared to present a reconstruction of the entire skull of Coahomasuchus based on the new material, but detail insights it provides on the skull roof, temporal region, and lower jaws here (Fig. 7).

Skull roof.-First, we note that, relative to Stagonolepis as described by Walker (1961; see also Gower and Walker, 2002) the skull roof of Coahomasuchus would be lower and flatter. We base this on the fact that, in lateral view, only the lateral ridge of the nasal is visible, the rest is relatively depressed, more so than in Stagonolepis robertsoni (Walker, 1961, fig. 2). Additionally, although there is evidence of some ornamentation on the frontals and parietals of Coahomasuchus chathamensis, it is faint and not as pronounced as in forms such as Stagonolepis olenkae (Sulej, 2010).

Temporal region.-Secondly, the postorbital is likewise not consistent with the condition reported in other aetosaurs, lacking a well-developed triangular process where it would have

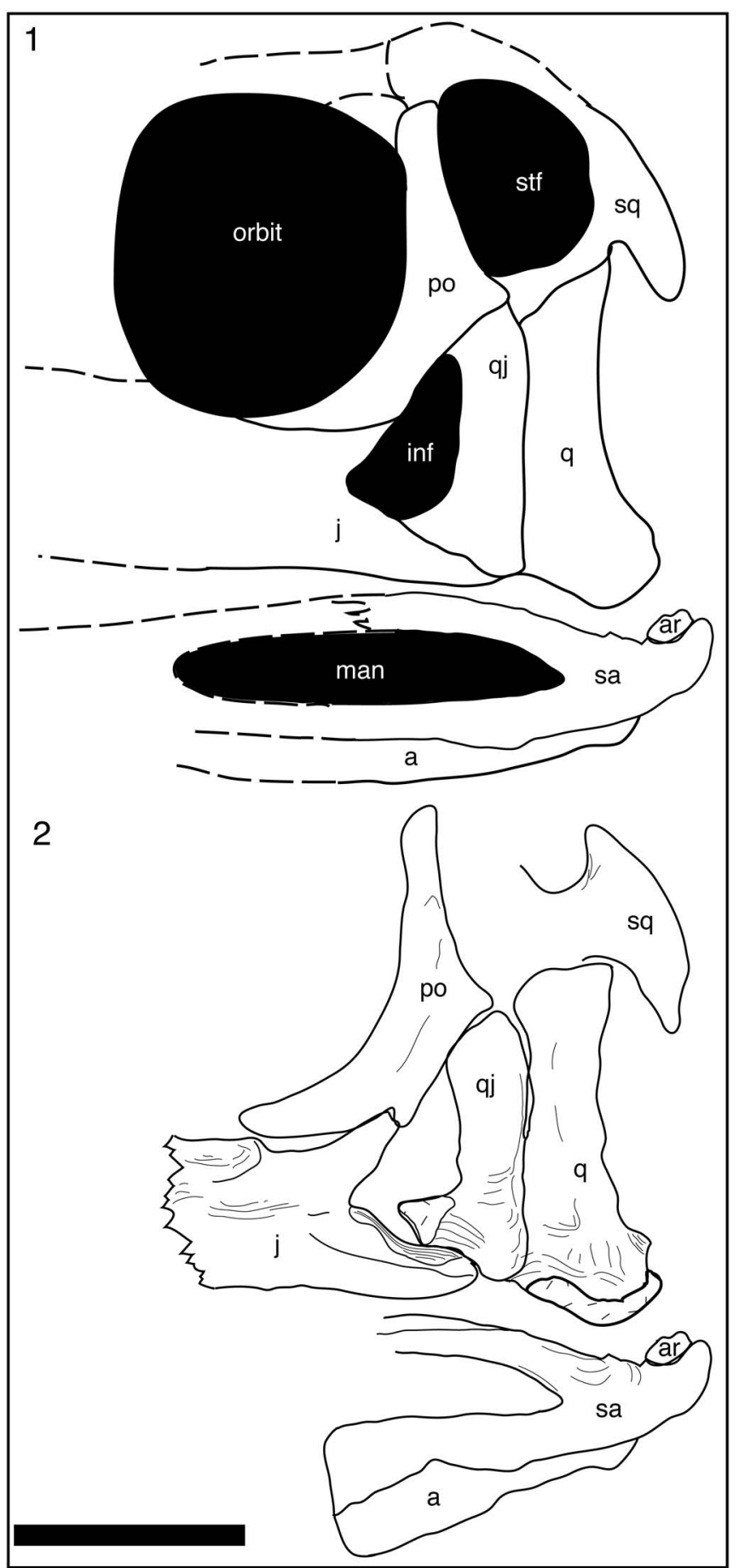

Figure 7. Tentative reconstructions of the posterior portion of the skull of Coahomasuchus chathamensis in left lateral view. (1) Reconstruction with dashed lines showing inferred/reconstructed bones. (2) Interpretive sketches of elements (many reversed) from previous figures rearticulated to show the basis of the reconstruction. $\mathrm{a}=$ angular; ar $=$ articular; inf $=$ infratemporal fenestra; $\mathrm{j}=$ jugal; $\operatorname{man}=$ mandibular fenestra; po = postorbital; $\mathrm{q}=$ quadrate; $\mathrm{qj}=$ quadratojugal $; \quad \mathrm{sa}=$ suragular; $\mathrm{sq}=$ squamosal $; \quad \mathrm{stf}=$ supratemporal fenestra. Scale bar represents $2 \mathrm{~cm}$. 
overlapped the squamosal (Fig. 7). In other aetosaurs, including Stagonolepis (Walker 1961, fig. 2; Sulej, 2010, fig. 4) Stenomyti (Small and Martz, 2013, fig. 4.11), and Desmatosuchus (Small, 2002, fig. 2a), the postorbital itself forms a pronounced posterior process that broadly overlaps the anterior edge of the squamosal. In Coahomasuchus it would appear that there was therefore a more reduced overlap of the squamosal. The occipital portion of the squamosal is also pronounced and most similar to Aetosaurus (compare Fig. 5.1, 5.2 to Desojo and Baéz, 2007, fig. 5; Schoch, 2007, fig. 5a).

Additionally, the jugal has a slender posterior process that contrasts with the condition in Desmatosuchus (Small, 2002, fig. 2a), where it is stouter and shorter. This is suggestive of a slightly longer lower temporal fenestra in Coahomasuchus chathamensis, a condition more reminiscent of Stagonolepis robertsoni (Walker, 1961, fig. 2) and Stenomyti (Martz and Small, 2013, fig. 11) (Fig. 7). Nevertheless our interpretations still favor a relatively small infratemporal fenestra, also seen in modern interpretations of Neoaetosauroides Desojo and Baéz, 2007, Aetosaurus (Schoch, 2007), Desmatosuchus (Small, 2002), and Paratypothorax (Schoch and Desojo, 2016), not the much larger infratemporal fenestra shown in many earlier reconstructions of aetosaurs such as Neoaetosauroides (Bonaparte, 1967, 1971).

Mandible and dentition.-The broad contact of the surangular over the angular is closer to the condition in Aetosaurus (e.g., Schoch, 2007, fig. 9b) than in Stagonolepis robertsoni (Walker, 1961, fig. 2c), although the surangular extends further posteriorly and ventrally in NCSM 23168 than in Aetosaurus (Fig. 7). Significantly, the ventral process of the surangular is at least as long as, or longer than, the dorsal process in Coahomasuchus chathamensis and quite unlike either Stagonolepis robertsoni (as illustrated by Walker 1961, fig. 6) or Stagonolepis olenkae (as illustrated by Sulej 2010, fig. 7) (Fig. 7). As a result the more ventral process of the surangular extends much further anteriorly than it does in either species of Stagonolepis (e.g., Walker, 1961; fig. 6) and Paratypothorax (Schoch and Desojo, 2016, fig. 6). Indeed such a condition has not been illustrated in any other aetosaur.

Finally, the preserved teeth are cylindrical to weakly recurved, and therefore plesiomorphic (Heckert and Lucas, 1999; Parker, 2007, 2016). They closely resemble those of Aetosaurus (Walker, 1961; Schoch, 2007) in lateral view, but are more cylindrical and less bulbous. The best preserved teeth are essentially round in cross-section and cylindrical (straightsided) in labial view for approximately $80 \%$ of their total height and are recurved at the tip. This condition appears to correspond with Parker's (2016) character state (1) for his character (35) except that the bases of the exposed teeth are essentially straight, and not conical, although we cannot be certain that these are maxillary teeth. The preserved teeth of Coahomasuchus chathamensis are less recurved than those Parker (2016) describes for the specimen he assigned to C. kahleorum (TMM 31100-437), but the comparison is complicated by the disarticulated nature of the holotype of $C$. chathamensis.

Armor.-Although the holotypes of both species of Coahomasuchus include skull and jaw material, neither is well preserved, and, given that osteoderm characters are often used to delineate aetosaurian taxa, it is the armor that ties these two species in the genus Coahomasuchus. In general, the osteoderms of NCSM 23168 strongly resemble those of NMMNH in P-18496, the holotype of C. kahleorum, but are considerably wider, with homologous paramedian osteoderms as much as $30 \%$ wider than their counterparts NMMNH P-18496. Exclusive of the paramedian osteoderms, NCSM 23168 is broadly comparable in size to the holotype of $C$. kahleorum. The proximal end of the humerus of NCSM 23168 is slightly wider ( $\sim 25$ to $\sim 23 \mathrm{~mm}$ ), but the braincases are equally as wide across the basipterygoid processes $(\sim 18 \mathrm{~mm})$. However, comparable dorsal paramedian osteoderms are always narrower in C. kahleorum than C. chathamensis. Osteoderms in approximately rows 14,15 in $C$. chathamensis are more than $90 \mathrm{~mm}$ wide, whereas they are only $\sim 75 \mathrm{~mm}$ wide in C. kahleorum. These differences are consistent regardless of whether the osteoderm width is measured in a straight line (dorsal view) or along the arc of the osteoderm. We are therefore confident that the two specimens represent distinct species.

The ornamentation of the osteoderms is remarkably similar, with extremely faint, subparallel grooves on the presacral paramedian osteoderms. As was the case in the holotype of Coahomasuchus kahleorum, this pattern is so faint that it is difficult to see any ornamentation on the cervical and thoracic paramedians. Similarly the dorsal eminences are extremely reduced, barely discernable in posterior view, and are expressed as very low longitudinal keels located much closer to the medial edge than the lateral one. These characteristics are apomorphic for Coahomasuchus in that the presacral paramedians of Coahomasuchus bear extremely faint ornamentation that, especially on the lateral side of the osteoderm, appears to consist almost entirely of sub parallel grooves and ridges to the exclusion of pits (Heckert and Lucas, 1999; Desojo and Heckert, 2004). We use the term "sub parallel" because the pits and ridges do not emanate in as radial a fashion as is typical in most aetosaurs, although perhaps this could be better quantified in the future. The only aetosaur with comparably faint ornamentation is Neoaetosauroides engaeus Bonaparte (1967, 1971; Desojo and Baéz, 2005), which has bosses that are both more distinct and situated closer to the middle of the osteoderm relative to Coahomasuchus and an ornamentation of more radially distributed grooves and ridges (Bonaparte, 1967, 1971; $\mathrm{ABH}$ pers. obs). Apachesuchus heckerti Spielmann and Lucas, 2012 has essentially no ornamentation, and is the only taxon with less distinct ornamentation than Coahomasuchus.

Lateral osteoderms in Coahomasuchus chathamensis are distinct in that the few $(\sim 3)$ relatively well preserved osteoderms in the holotype carapace are more deeply incised with a pattern of deeply incised pits with few, if any grooves compared to those of C. kahleorum. Many of the isolated lateral osteoderms, however, more closely match posterior (mid-thoracic, sacral, and caudal) lateral osteoderms of C. kahleorum. We note that the asymmetrical shape of the laterals, with a narrower dorsal flange and broader lateral flange separated by a longitudinal keel was not originally reported in C. kahleorum by Heckert and Lucas (1999) but is clear from both the published illustrations (Heckert and Lucas, 1999, fig. 3) and our examination of a cast of that specimen. Indeed, we labeled such osteoderms as laterals in earlier presentations of this material (Fraser et al., 2007; Schneider et al., 2011). In his recent dissertation Parker (2014, 
see also Parker, 2016) independently redescribed the lateral osteoderms and several other aspects of $C$. kahleorum as well.

The taxonomic significance of isolated osteoderms has been hotly debated, but many taxa remain known solely from osteoderms, and osteoderm characters provide abundant information used in cladistic hypotheses of aetosaur relationships (Heckert and Lucas, 1999, 2000; Parker, 2007, 2016; Heckert et al., 2015). Therefore, the preservation of two carapaces of Coahomasuchus provides an opportunity to test hypotheses regarding the nature of variation in osteoderms. Certainly there is variation in the shape and proportions of dorsal paramedian osteoderms to accomplish changes in carapace shape posteriorly through the column. However, we note that all of the osteoderms described here have the same fundamental ornamentation pattern, and that this particular pattern has only been reported for Coahomasuchus (Heckert and Lucas, 1999; Desojo et al., 2013; Parker, 2016). Similarly, the laterals, which are relatively plesiomorphic, are still remarkably consistent in shape and ornamentation pattern between the two skeletons. We interpret this to show that the markedly greater width of C. chathamensis is a real taxonomic feature, not a result of intraspecific variation based on age or sex.

\section{Discussion}

Coahomasuchus chathamensis is important because it represents a new taxon closely related to $C$. kahleorum, which is otherwise only known with certainty from NMMNH locality 3357 in the Colorado City Formation of west Texas. Importantly, as documented previously, $C$. chathamensis is definitely wider-bodied than $C$. kahleorum and the isolated, but referred, osteoderms from NCPALEO1902 indicate that the maximum size of Coahomasuchus is definitely larger than either preserved holotype specimen.

Cranial material of aetosaurs is not particularly well known, so this new record is important as it permits additional insights into the skull of Coahomasuchus not available to Lucas and Heckert (1999) or Desojo and Heckert (2004). If the right quadratojugal in NCSM 23618 is correctly identified, then the broad contact between the squamosal and the quadratojugal as depicted in Stagonolepis and many other aetosaurs is not present in C. chathamensis (Fig. 7). However, it should be pointed out that this region of the skull is rather poorly preserved in the majority of specimens of other described taxa, including Longosuchus, Aetosaurus and Neoaetosauroides, and we suspect that the restorations of these taxa may have been influenced by the condition reported in Stagonolepis (Walker, 1961).

Coahomasuchus chathamensis is notable for its relatively wide osteoderms as preserved in both the anterior carapaces of the holotype as well as in several of the isolated osteoderms (e.g., NCSM 16444-1-Fig. 6.2). Indeed, NCSM 16444-1, while incomplete, has a $\mathrm{W}: \mathrm{L}$ ratio of 3.6:1. This is comparable to the ratios of known wide-bodied taxa such as Typothorax, Paratypothorax, and Tecovasuchus (Typothoracisinae of Parker, 2007; Desojo et al., 2013; emended to Typothoracinae by Parker, 2016), all of which have multiple paramedian osteoderms with $\mathrm{W}: \mathrm{L}$ ratios exceeding 3.5:1 and some as wide as 4:1 (Heckert and Lucas, 2000; Martz and Small, 2006; Desojo et al., 2013). Unlike these taxa, however,
C. chathamensis lacks spinose lateral armor. Because of the incomplete nature of the Pekin Formation fossils, we only tentatively note that it is possible that Coahomasuchus marks an early acquisition of a wider body plan that is probably independent of (and convergent with) that of typothoracisines. Because Coahomasuchus is older than any of the other widebodied taxa, this marks the earliest evidence we have of an aetosaur evolving a relatively wide body, with paramedian osteoderms attaining $\mathrm{W}: \mathrm{L}$ ratios of as much as 3.5:1. Interestingly, Parker (2016, fig. 8A) recovers Coahomasuchus in a somewhat later branching position, closely related to Typothorax and Paratypothorax, so coding $C$. chathamensis identically to C. kahleorum except for Parker's (2016) character 64, which would code as "2" like Typothorax and Paratypothorax, would almost certainly strengthen that relationship.

Phylogeny.-As we prepared to submit this article two new phylogenetic hypotheses of aetosaurs appeared in the literature (Parker, 2016; Schoch and Desojo, 2016). Of these, we discuss Schoch and Desojo's (2016) analysis, which we find problematic, first, before addressing how Coahomasuchus chathamensis may affect Parker's (2016) analysis.

Like most recent phylogenies, Schoch and Desojo (2016) effectively used the character matrix of Parker (2007) as updated by some later authors (Parker et al., 2008; Parker and Martz, 2010; Desojo et al., 2012; da-Silva et al., 2014). Although Schoch and Desojo (2016) did add seven new cranial characters to the analysis, they chose not to incorporate updates and corrections to the main body of the matrix we published when we named Gorgetosuchus (Heckert et al., 2015), in spite of the fact that Gorgetosuchus was published well prior to their paper. This is important, because not only did we add Gorgetosuchus to the taxon list, but we included a total of eleven scoring changes for Lucasuchus, Longosuchus, Typothorax, Redondasuchus, and Coahomasuchus, the latter based on our observations of the material described here. Thus, Schoch and Desojo (2016) effectively reused the da-Silva et al. (2014) version of the matrix without Gorgetosuchus or eight of the eleven coding changes we recommended (nor did they cite Heckert et al. [2015], so it is unclear why they made the changes they did). In light of the omissions of Schoch and Desojo (2016) we are skeptical of their results, particularly their finding of Coahomasuchus as a "wildcard taxon" that prevented them from achieving a well-resolved tree in their main analysis.

Of the seven characters novel to Schoch and Desojo's (2016) analysis, we can only update one scoring, coding Coahomasuchus as (1) for the their character 43 (squamosal included or excluded from the infratemporal fenestra by the postorbital-quadratojugal contact). The posterior process of the postorbital we have described here articulates with the quadratojugal and effectively excludes the squamosal from the infratemporal fenestra (Fig. 7).

Parker's (2016) analysis built off his (2014) dissertation and incorporates many more characters (83) than any previous study. Unlike Schoch and Desojo (2016), he incorporated Gorgetosuchus and at least some of the character scoring changes we (Heckert et al., 2015) advocated, with the caveat that he also overhauled many of the characters. We therefore consider his analysis more robust generally and far more likely 
to accurately present a reasonable hypothesis for the phylogenetic position of Coahomasuchus.

We have evaluated Parker's (2016) phylogeny, in particular his coding of Coahomasuchus, although we reserve judgment on his referral of the unpublished and undescribed "carnivorous aetosaur" specimen (TMM 31100-437) to Coahomasuchus kahleorum. This specimen is not available to us for study, has only appeared in the literature in an abstract (Murry and Long, 1996), and is neither illustrated nor described by Parker (2016), so we do not include it in our list of specimens. It is apparent from close examination of Parker's (2016) matrix that this specimen is critical to his concept of Coahomasuchus, and that many of his codings, particularly of cranial, jaw, and dental material, are based on his observations of TMM 31100-437. It is from the same area (Otis Chalk) and stratigraphic unit (Colorado City Formation of our usage) as the holotype of Coahomasuchus kahleorum, so it adds little if anything to the paleogeographic range and stratigraphic distribution of the genus.

Like Heckert et al. (2015), Parker (2016) found that Aetobarbakinoides, not Coahomasuchus, is problematic, largely because its osteoderms are almost entirely unknown and thus cannot be scored nor provide insight to its relationships with the many taxa known solely from osteoderms. Otherwise, the observable features of the holotype of $C$. chathamensis score identically to $C$. kahleorum, with the exception of the maximum width of the paramedian osteoderms, so the addition of this new species is unlikely to change the phylogenetic position of the genus.

Distribution and age.-Previously, the only published specimen of Coahomasuchus was the holotype of C. kahleorum from the Colorado City Formation of West Texas. This marks the first occurrence of Coahomasuchus from outside the American Southwest. The Pekin Formation of North Carolina shares the presence of another aetosaur, Lucasuchus, with the Colorado City Formation as well (Parker and Martz, 2010). This reinforces past correlations of lowermost "Dockum" strata in Texas with the Carnian-aged portion of the Newark Supergroup (e.g, Lucas and Huber, 2003). In this case the correlation is established at the genus level, not the species level, but it is nonetheless indicative that at least some Upper Triassic strata in the American Southwest may in fact be Carnian, not Norian, in age, regardless of the duration of the Norian.

\section{Conclusions}

Coahomasuchus chathamensis from the Pekin Formation of North Carolina is the first occurrence of the genus from outside of the American Southwest, the second aetosaur named from the Pekin Formation, and only the second aetosaur identifiable to species from North Carolina. The carapace is the stratigraphically oldest record of a wide-bodied aetosaur (W:L of dorsal paramedian osteoderms $\geq 3.5: 1$ ), although it is too incomplete to determine if it had the fully discoidal carapace that characterizes taxa such as Typothorax and Paratypothorax. Finally, because aetosaur skulls are relatively uncommon, the skull described here provides additional insight into morphological features, not just of Coahomasuchus, but of aetosaurs generally.

\section{Acknowledgments}

Volunteers and staff at the NCSM, including V. Lee and T. Weaver, helped find and collect the fossils described here. We thank the company that owns the property, although they wish to remain anonymous. R. Chandler executed some of the photographs of the specimen. The NMMNH provided a cast of the holotype of Coahomasuchus kahleorum for comparison. Discussions with P. E. Olsen clarified the stratigraphy of the quarry area. M. Celeskey provided additional information from his study of the holotype of C. kahleorum. Reviewers W. Parker and T. Sulej provided helpful reviews of an earlier version of this manuscript, which was handled by editors B. Hunda and M. Langer.

\section{References}

Bonaparte, J. F., 1967, Dos nuevas "faunas" de reptiles Triasicos de Argentina: Gondwana Symposium Proceedings and Papers, v. 1, p. 283-306.

Bonaparte, J. F., 1971, Los tetrapodos del sector superior de la formacion Los Colorados, la Rioja, Argentina (Triásico Superior) I Parte.: Opera Lillona, v. 22 , p. $1-183$.

Campbell, M. R., and Kimball, K. K., 1923, The Deep River coal field of North Carolina: North Carolina Geological and Economic Survey Bulletin, v. 33, p. $1-95$.

Case, E. C., 1922, New reptiles and stegocephalians from the Upper Triassic of western Texas: Carnegie Institution Publication, v. 321, 84 p.

Cope, E. C., 1869, Synopsis of the extinct Batrachia, Reptilia, and Aves of North America: Transactions of the American Philosophical Society, v. 14, 252 p.

Cornet, B., 1993, Applications and limitations of palynology in age, climatic, and paleoenvironmental analyses of Triassic sequences in North America: New Mexico Museum of Natural History and Science Bulletin, v. 3, p. 75-93.

da-Silva, L. R., Desojo, J. B., Cabreira, S. F., Aires, A. S. S., Müller, R. T., Pacheco, C. P., and Dias-da-Silva, S., 2014, A new aetosaur from the Upper Triassic of the Santa Maria Formation, southern Brazil: Zootaxa, v. 3764, p. 240-278.

Desojo, J. B., and Báez, A. M., 2005, El esquelto postcraneano de Neoaetosauroides (Archosauria: Aetosauria) del Triásico Superior del centro-oeste de Argentina: Ameghiniana, v. 42, p. 115-126.

Desojo, J. B., and Báez, A. M., 2007, Cranial morphology of the Late Triassic South American archosaur Neoaetosauroides engaeus: evidence for aetosaurian diversity: Palaeontology, v. 50, p. 267-276.

Desojo, J. B., and Heckert, A. B., 2004, New information on the braincase and mandible of Coahomasuchus (Archosauria: Aetosauria) from the Otischalkian (Carnian) of Texas: Neues Jahrbuch für Geologie und Paläontologie Monatsheft, v. 2004, p. 605-616.

Desojo, J. B., Ezcurra, M. D., and Kischlat, E.-E., 2012, A new aetosaur genus (Archosauria: Pseudosuchia) from the early Late Triassic of southern Brazil: Zootaxa, v. 3166, p. 1-33.

Desojo, J. B., Heckert, A. B., Martz, J. W., Parker, W. G., Schoch, R. R., Small, B. J., and Sulej, T., 2013, Aetosauria: a clade of armoured pseudosuchians from the Late Triassic continental beds: Geological Society, London, Special Publications, v. 379, p. 203-239.

Drymala, S. M., and Zanno, L. E., 2016, Osteology of Carnufex carolinensis (Archosauria: Psuedosuchia) from the Pekin Formation of North Carolina and its implications for early crocodylomorph evolution: PLoS ONE, v. 11, no. 6, p. e0157528.

Fraser, N. C., Heckert, A. B., Lucas, S. G., and Schneider, V.P., 2006, The first record of Coahomasuchus (Archosauria: Stagonolepididae) from the Carnian of eastern North America: Journal of Vertebrate Paleontology, v. 26, supplement to no. 3, p. 63A

Furin, S., Preto, N., Rigo, M., Roghi, G., Gianolla, P., Crowley, J. L., and Bowring, S. A., 2006, High-precision U-Pb zircon age from the Triassic of Italy: Implications for the Triassic time scale and the Carnian origin of calcareous nannoplankton and dinosaurs: Geology, v. 34, p. 1009-1012.

Gower, D. J., and Walker, A. D., 2002, New data on the braincase of the aetosaurian archosaur (Reptilia: Diapsida) Stagonolepis robertsoni Agassiz: Zoological Journal of the Linnean Society, v. 136, p. 7-23.

Green, J. L., 2012, Bone and dental histology of Late Triassic dicynodonts from North America, in Chinsamy-Turan, A., ed., Forerunners of mammals: Radiation, Histology, Biology: Bloomington, Indiana University Press, p. $178-196$. 
Green, J. L., Schneider, V. P., Scheitzer, M., and Clarke, J., 2005, New evidence for non-Placerias dicynodonts in the Late Triassic (Carnian-Norian) of North America: Journal of Vertebrate Paleontology, v. 25, supplement to no. 3, p. 65-66.

Heckert, A. B., and Lucas, S. G., 1999, A new aetosaur (Reptilia: Archosauria) from the Upper Triassic of Texas and the phylogeny of aetosaurs: Journal of Vertebrate Paleontology, v. 19, p. 50-68.

Heckert, A. B., and Lucas, S. G., 2000, Taxonomy, phylogeny, biostratigraphy, biochronology, paleobiogeography, and evolution of the Late Triassic Aetosauria (Archosauria:Crurotarsi): Zentralblatt für Geologie und Paläontologie Teil I, v. 1998, Heft 11-12, p. 1539-1587.

Heckert, A. B., Schneider, V. P., and Fraser, N. C., 2012, Two new aetosaurs (Reptilia:Archosauria) from the Upper Triassic Pekin Formation (Deep River Basin: Newark Supergroup) of North Carolina and the phylogeny and distribution of aetosaurs: Geological Society of America Abstracts with Programs, v. 44, no. 7, p. 233.

Heckert, A. B., Jenkins, H. S., Hunt, A. P., and Lucas, S. G., 2013, Mandibles of juvenile phytosaurs (Archosauria:Crurotarsi) from the Upper Triassic Chinle Group of Texas and New Mexico, USA: New Mexico Museum of Natural History and Science Bulletin, v. 61, p. 228-236.

Heckert, A. B., Schneider, V. P., Fraser, N. C., and Webb, R. A., 2015, A new aetosaur (Archosauria, Stagonolepididae) from the Upper Triassic Pekin Formation, Deep River Basin, North Carolina, U.S.A. and its implications for early aetosaur evolution: Journal of Vertebrate Paleontology, v. 35, e88131; 13 p.

Huber, P., Lucas, S. G., and Hunt, A. P., 1993, Revised age and correlation of the Upper Triassic Chatham Group (Deep River Basin, Newark Supergroup), North Carolina: Southeastern Geology, v. 33, p. 171-193.

Kent, D. V., and Olsen, P. E., 1999, Astronomically tuned geomagnetic polarity timescale for the Late Triassic: Journal of Geophysical Research, v. 104, no. B6, p. 12,831-12,841.

Kent, D. V., and Olsen, P. E., 2000, Implications of astronomical climate cycles to the chronology of the Triassic: Zentralblatt für Geologie und Paläontologie Teil I, v. 1998, no. Heft 11-12, p. 1463-1473.

Krebs, B., 1974, Die Archosaurier: Die Naturwissenschaften, v. 61, p. 17-24.

Litwin, R. J., and Ash, S. R., 1993, Revision of the biostratigraphy of the Chatham Group (Upper Triassic), Deep River basin, North Carolina, USA: Review of Palaeobotany and Palynology, v. 77, p. 75-95.

Liu, J., and Sues, H. D., 2010, Dentition and tooth replacement of Boreogomphodon (Cynodontia: Traversodontidae) from the Upper Triassic of North Carolina, USA: Vertebrata PalAsiatica, v. 48, p. 169-184.

Long, R. A., and Ballew, K. L., 1985, Aetosaur dermal armor from the Late Triassic of southwestern North America, with special reference to material from the Chinle Formation of Petrified Forest National Park: Museum of Northern Arizona Bulletin, v. 47, p. 45-68.

Long, R. A., and Murry, P. A., 1995, Late Triassic (Carnian and Norian) tetrapods from the southwestern United States: New Mexico Museum of Natural History and Science Bulletin, v. 4, 254 p.

Lucas, S. G., 2010, ed., The Triassic timescale, Geological Society, London, Special Publications: London, The Geological Society of London, v. 334, $514 \mathrm{p}$.

Lucas, S. G., and Huber, P., 2003, Vertebrate biostratigraphy and biochronology of the nonmarine Late Triassic, in LeTourneau, P. M., and Olsen, P. E., eds. The great rift valleys of Pangea in Eastern North America: Sedimentology, Stratigraphy, and Paleontology: New York, Columbia University Press, p. 143-191.

Lucas, S. G., Heckert, A. B., and Hunt, A. P., 2002, A new species of the aetosaur Typothorax (Archosauria: Stagonolepididae) from the Upper Triassic of east-central New Mexico: New Mexico Museum of Natural History and Science Bulletin, v. 21, p. 221-233.

Lucas, S. G., Hunt, A. P., and Spielmann, J. A., 2006, Rioarribasuchus, a new name for an aetosaur from the Upper Triassic of north-central New Mexico: New Mexico Museum of Natural History and Science Bulletin, v. 37, p. $581-582$.

Lucas, S. G., Hunt, A. P., and Spielmann, J. A., 2007, A new aetosaur from the Upper Triassic (Adamanian: Carnian) of Arizona: New Mexico Museum of Natural History and Science Bulletin, v. 40, p. 241-247.

Lucas, S. G., Tanner, L. H., Kozur, H. W., Weems, R. E., and Heckert, A. B., 2012, The Late Triassic timescale: Age and correlation of the CarnianNorian boundary: Earth-Science Reviews, v. 114, p. 1-18.

Lydekker, R., 1887, The fossil Vertebrata of India: Records of the Geological Survey of India, v. 20, p. 51-80.

Marsh, O. C., 1884, The classification and affinities of dinosaurian reptiles: Nature, v. 31, p. 68-69.

Martz, J. W., and Small, B. J., 2006, Tecovasuchus chatterjeei, a new aetosaur (Archosauria: Stagonolepididae) from the Tecovas Formation (Carnian, Upper Triassic) of Texas: Journal of Vertebrate Paleontology, v. 26, p. $308-320$.
Murry, P. A., and Long, R. A., 1996, A diminutive carnivorous aetosaur from the Upper Triassic of Howard County, Texas: Journal of Vertebrate Paleontology, v. 16, supplement to no. 3, p. 55A.

Muttoni, G., Kent, D. V., Olsen, P. E., Stefano, P. d., Lowrie, W., Bernasconi, S. M., and Hernández, F. M., 2004, Tethyan magnetostratigraphy from Pizzo Mondello (Sicily) and correlation to the Late Triassic Newark astrochronological polarity time scale: Geological Society of America Bulletin, v. 116, p. 1043-1058.

Nesbitt, S. J., 2011, The early evolution of archosaurs: relationships and the origin of major clades: Bulletin of the American Museum of Natural History, v. 352, 292 p.

Olsen, P. E., 1997, Stratigraphic record of the early Mesozoic breakup of Pangea in the Laurasia-Gondwana rift system: Annual Review of Earth and Planetary Sciences, v. 25, p. 337-401.

Olsen, P. E., Froehlich, A. J., Daniels, D. L., Smoot, J. P., and Gore, P. J. W., 1991, Rift basins of early Mesozoic age, in Horton, J. W., Jr., and Zullo, V. A., eds., Geology of the Carolinas: Knoxville, University of Tennessee Press, p. 142-170.

Parker, W. G., 2005, A new species of the Late Triassic aetosaur Desmatosuchus (Archosauria: Pseudosuchia): Comptes Rendus Palevol, v. 4, p. $327-340$.

Parker, W. G., 2007, Reassessment of the aetosaur 'Desmatosuchus' chamaensis with a reanalysis of the phylogeny of the Aetosauria (Archosauria: Pseudosuchia): Journal of Systematic Palaeontology, v. 5, p. 41-68.

Parker, W. G., 2014, Taxonomy and phylogeny of the Aetosauria (Archosauria: Pseudosuchia) including a new species from the Upper Triassic of Arizona [PhD Dissertation thesis]: University of Texas, $437 \mathrm{p}$.

Parker, W. G., 2016, Revised phylogenetic analysis of the Aetosauria (Archosauria: Pseudosuchia); assessing the effects of incongruent morphological character sets: PeerJ, v. 4, e1583, DOI 10.7717/peerj.1583.

Parker, W. G., and Martz, J. W., 2010, Using positional homology in aetosaur (Archosauria: Pseudosuchia) osteoderms to evaluate the taxonomic status of Lucasuchus hunti: Journal of Vertebrate Paleontology, v. 30, p. $1100-1108$.

Parker, W. G., Stocker, M. R., and Irmis, R. B., 2008, A new desmatosuchine aetosaur (Archosauria: Suchia) from the Upper Triassic Tecovas Formation (Dockum Group) of Texas: Journal of Vertebrate Paleontology, v. 28, p. 692-701.

Parrish, J. M., 1994, Cranial osteology of Longosuchus meadei and the phylogeny and distribution of the Aetosauria: Journal of Vertebrate Paleontology, v. 14, p. 196-209.

Reinemund, J. A., 1955, Geology of the Deep River Coal Field: United States Geological Survey Professional Paper, v. 246, 159 p.

Sawin, H. J., 1947, The pseudosuchian reptile Typothorax meadei: Journal of Paleontology, v. 21, p. 201-238.

Schneider, V., Heckert, A. B., and Fraser, N. C., 2011, Diversity of aetosaurs (Archosauria:Stagonolepididae) from the Upper Triassic Pekin Formation (Deep River Basin), North Carolina: Journal of Vertebrate Paleontology, SVP Program and Abstracts Book, v. 2011, p. 188.

Schoch, R. R., 2007, Osteology of the small archosaur Aetosaurus from the Upper Triassic of Germany: Neues Jahrbuch für Geologie und Paläontologie Abhandlungen, v. 246, p. 1-35.

Schoch, R. R., and Desojo, J. B., 2016, Cranial anatomy of the aetosaur Paratypothorax andressorum Long \& Ballew, 1985, from the Upper Triassic of Germany and its bearing on aetosaur phylogeny: Neues Jahrbuch für Geologie und Paläontologie Monatsheft, v. 279, p. 73-95.

Small, B. J., 2002, Cranial anatomy of Desmatosuchus haplocerus (Reptilia: Archosauria: Stagonolepididae): Zoological Journal of the Linnean Society, v. 136, p. $97-111$.

Small, B. J., and Martz, J. W., 2013, A new aetosaur from the Upper Triassic Chinle Formation of the Eagle Basin, Colorado, USA: Geological Society, London, Special Publications, v. 379, p. 393-412.

Spielmann, J. A., and Lucas, S. G., 2012, Tetrapod fauna of the Upper Triassic Redonda Formation, east-central New Mexico: The characteristic assemblage of the Apachean land-vertebrate faunachron: New Mexico Museum of Natural History and Science Bulletin, v. 55, 119 p.

Sulej, T., 2010, The skull of an early Late Triassic aetosaur and the evolution of the stagonolepidid archosaurian reptiles: Zoological Journal of the Linnean Society, v. 158 , p. $860-881$.

Walker, A. D., 1961, Triassic reptiles from the Elgin area: Stagonolepis, Dasygnathus, and their allies: Philosophical Transactions of the Royal Society of London, B, v. 244, p. 103-204.

Weems, R. E., and Olsen, P. E., 1997, Synthesis and revision of groups within the Newark Supergroup, eastern North America: Geological Society of America Bulletin, v. 109, p. 195-209.

Whiteside, J. H., Grogan, D. S., Olsen, P. E., and Kent, D. V., 2011, Climatically driven biogeographic provinces of Late Triassic tropical Pangea: Proceedings of the National Academy of Science, v. 108, p. 8972-8977. 
Zanno, L. E., Drymala, S., Nesbitt, S. J., and Schneider, V. P., 2015, Early crocodylomorph increases top tier predator diversity during rise of dinosaurs: Science Reports, v. 5, no. 9276, 5 p. http://dx.doi.org/10.1038/ srep09276.

Zeigler, K. E., Heckert, A. B., and Lucas, S. G., 2002, A new species of Desmatosuchus (Archosauria: Aetosauria) from the Upper Triassic of the
Chama Basin, north-central New Mexico: New Mexico Museum of Natural History and Science Bulletin, v. 21, p. 215-219.

Accepted 2 August 2016 